Article

\title{
Experimental Investigation of Micro Cooling Units on Impingement Jet Array Flow Pressure Loss and Heat Transfer Characteristics
}

\author{
Zhong Ren, Xiaoyu Yang, Xunfeng Lu, Xueying Li * and Jing Ren
}

Citation: Ren, Z.; Yang, X.; Lu, X.; Li, $X . ;$ Ren, J. Experimental Investigation of Micro Cooling Units on

Impingement Jet Array Flow Pressure Loss and Heat Transfer

Characteristics. Energies 2021, 14, 4757. https://doi.org/10.3390/ en14164757

Academic Editor: Bruno Facchini

Received: 2 July 2021

Accepted: 27 July 2021

Published: 5 August 2021

Publisher's Note: MDPI stays neutral with regard to jurisdictional claims in published maps and institutional affiliations.

Copyright: (c) 2021 by the authors. Licensee MDPI, Basel, Switzerland. This article is an open access article distributed under the terms and conditions of the Creative Commons Attribution (CC BY) license (https:// creativecommons.org/licenses/by/ $4.0 /)$.
Department of Energy and Power Engineering, Tsinghua University, Beijing 100084, China; zren@mail.tsinghua.edu.cn (Z.R.); Xiaoyu-y19@mails.tsinghua.edu.cn (X.Y.); xflu@stanford.edu (X.L.); renj@tsinghua.edu.cn (J.R.)

* Correspondence: li_xy@tsinghua.edu.cn

\begin{abstract}
With the development in additive manufacturing, the use of surface treatments for gas turbine design applications has greatly expanded. An experimental investigation of the pressure loss and heat transfer characteristics within impingement jet arrays with arrays of target surface micro cooling units is presented. The discharge coefficient and Nusselt number are measured and determined for an evaluation of the pressure loss of the flow system and heat transfer level, respectively. Considered are effects of impingement jet Reynolds number ranging from 1000 to 15,000 and micro cooling units (square pin fin) height (h) with associated values of $0.01,0.02,0.05,0.2$, and $0.4 \mathrm{D}$, where $\mathrm{D}$ is the impingement hole diameter. Presented are variations of Nusselt number, and Nusselt number ratio, discharge coefficient, discharge coefficient ratio, discharge coefficient correlation. Depending upon the micro cooling unit height, discharge coefficient ratios slightly decrease with height, and the ratio values generally remain unit value (1.0). When $\operatorname{Re}_{j}=1000$ and 2500 for several cooling units height values, discharge coefficient ratios show the pressure loss decreases about $2-18 \%$ and $3-6 \%$, respectively, when compared to the data of a baseline smooth target surface plate. The observed phenomenon is due to the effects of flow blockage of micro cooing units, local flow separation, and near-wall viscous sublayer reattachment. Results also show that heat transfer levels increase $20-300 \%$ for some of the tested toughened target surface plates when compared to smooth target surface plates. The heat transfer level enhancement is because of an increase in thermal transport and near-wall mixing, as well as the increased wetted area. In addition, micro cooling units elements break the viscous sublayer and cause greater turbulence intensity when compared to the smooth target surface. Overall, results demonstrate that the target surface micro cooling units do not result in a visible increment in pressure loss and reduce pressure loss of the flow system for some of the tested patterns. Moreover, results show the significant ability of micro cooling units to enhance the surface heat transfer capability of impingement cooling relative to smooth target surfaces.
\end{abstract}

Keywords: heat transfer; gas turbine; impingement cooling; surface treatments; micro cooling units

\section{Introduction}

In the turbomachinery industry, a cooling system plays an important role in protecting all components exposed to hot gas. Impingement cooling is widely used to manage the heat load of an aero-engine [1]. Significant improvement of impingement target surface design has been made in gas turbine design, mainly due to the push of increasing turbine inlet temperature and turbine pressure ratio. However, the existing configurations of cooling structures enhance heat transfer with a severe pressure drop penalty. Despite the heat transfer augmentation levels of impingement cooling, pressure loss reduction for such configurations remains an important and challenging issue. Moreover, the flow is far beyond being sufficiently understood due to the complexity of flow features. With 
these associated limitations, the resulting challenges mean more efficient cooling methods are required [2]. This paper focuses on pressure loss and heat transfer characteristics of impingement jet array flow.

A number of researchers investigate impingement jet array cooling with different configurations. Kercher et al. [3], Chance et al. [4], San et al. [5], and Lee et al. [6] consider the effects of jet-to-target surface distance with relatively low flow speed. Two widely cited studies are presented by Florschuetz et al. [7] and Metzger et al. [8]. These investigators indicate the effects of inline/stagger jet impingement hole patterns on cooling effectiveness. Bailey and Bunker [9] and Lee et al. [6,10] present the effects of impingement jet Reynolds number.

To enhance the heat transfer levels of impingement cooling, other investigators consider applying surface treatments on impingement target surfaces. Warren et al. [11] and Ligrani et al. [12] describe the influence of roughness distribution, shapes, and sizes on impingement heat transfer. Data illustrate the fantastic ability of surface roughness for heat transfer enhancement of impingement jet array cooling. Ren et al. [13] consider multiple target surface treatment patterns on impingement target surfaces and describe that roughness element shapes with sharp edges generate an increasing magnitude of vorticity with the length scale of the surface roughness element diameter. Nakamata et al. [14] evaluate the effects of cooling hole shape and roughened elements on impingement cooling effectiveness. Results show that increment of heat transfer level for concave structures (ribs and bumps) are through wetted area enhancement.

The concept of enhancing impingement jet array heat transfer levels by using roughened target surfaces has been studied in some investigations. However, considering the remarkable ability of surface heat transfer level augmentation at a relatively low-pressure loss penalty, the available literature is relatively insufficient. Singh and Ekkad [15] investigate the effects of various-shaped roughness on array jet impingement cooling. Authors demonstrate that when compared to a smooth surface target plate, a roughed plate yields about $20 \%$ to $40 \%$ enhancement in effectiveness without showing a discernable pressure drop penalty. Spring et al. [16] investigate impingement cooling with the rib-roughened target surface. The width and height of the tested rib are $1 \mathrm{D}$, where $\mathrm{D}$ is the jet hole diameter. Results show that the surface elements do not cause significant pressure drop increment for the flow system. Brakmann et al. [17] investigate the pressure drop and heat transfer characteristics of an impingement jet array on a roughened surface target plate by cubic micro pin fins. The investigated pin fin has a length of $0.22 \mathrm{D}$ and increases the surface area up to $250 \%$. Overall, when compared to a smooth surface target plate, the roughened plate increases the heat flux and pressure loss up to $134 \%-142 \%$ and $14 \%$, respectively.

The present investigation is based upon an experimental investigation of impingement jet array flow pressure loss and heat transfer characteristics onto the target surface roughened with an array of micro cooling units. The cooling units shape studied is micro square pin fin, with height values of 0.01, 0.02, 0.05, 0.2, and 0.4 D. Experiments are tested at impingement jet Reynolds numbers of 1000, 2500, 5000, 10,000, and 15,000. Of particular interest are various spatially averaged Nusselt numbers, spatially averaged Nusselt number ratio, discharge coefficient ratios, and discharge coefficient correlation.

\section{Materials and Methods}

The apparatus and procedures of the micro cooling units surface impingement cooling experimental facility at the Tsinghua University in Beijing, P.R. China are presented. Relevant details of measurement and parameter determinations are included.

\subsection{Impingement Flow Facility}

Figure 1 shows schematic diagrams of the facility used for the present investigation, including heat transfer and pressure loss measurements. The impingement flow channel consists of a converging nozzle, a flow measurement segment, an expansion nozzle, the test section, an exhaust plenum, and a blower. A Bestace thermal mass flow meter is installed 
in the measurement segment to measure the mass flow rate. Flow straighten devices are installed downstream of the expansion section. The expansion nozzle has a square-shaped cross-section with a 5-degree divergent angle. Airflow is induced through the impingement channel by means of suction, which is generated by a pressure blower at the exit of the flow passage. One Kiel probe and one thermocouple are used to measure the supply chamber air inlet total pressure and temperature. Excluding the test section and blower, the rest of the facility is constructed of steel.

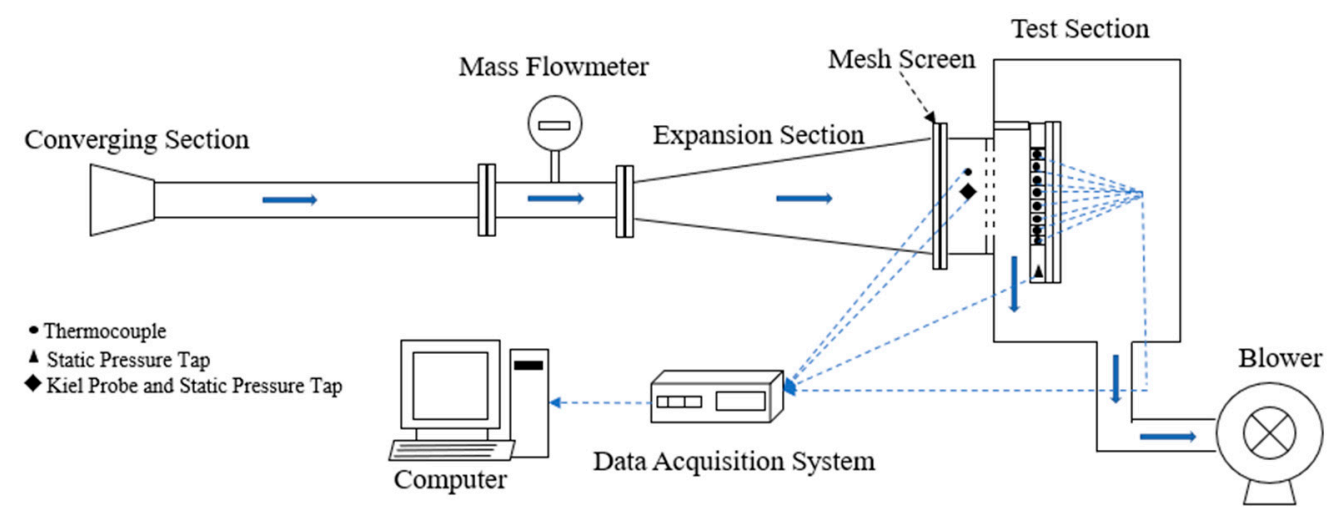

Figure 1. Impingement cooling test facility.

\subsection{Test Section and Test Surface}

Figure 2 shows a schematic diagram of the impingement test section. The test section is mounted on the side of the impingement plenum, including pressure measurement instrumentation installation. In general, the test section consists of a plenum, associated test frame components. The frame structure and impingement plate are made of optically transparent acrylic. The components of the flow passage and the target surface plate are designed for minimized air leakage and heat loss. The present study uses one impingement plate.

In Figure 2, the impingement target plate consists of a copper bar, where each bar is $150.0 \mathrm{~mm}$ long, $23 \mathrm{~mm}$ wide, and $10 \mathrm{~mm}$ thick, shown in Figures 2 and 3 . Eight copper bars are arranged and installed at the bottom of the test section with insulation materials between the adjacent copper bar. With this design, each of the copper bars performs as a regional heat transfer impingement target surface that is maintained under a constant temperature. Three machined holes are designed to install thermocouples for temperature measurement. An ultra-thin-film heater is used for constant heat flux. The insulation layer reduces heat losses from below heaters and air leakage. For the present arrangement, the associated temperature of the copper bar is ranging from 30 to $100^{\circ} \mathrm{C}$. A listing of all micro cooling units configurations investigated is shown in Table 1. 

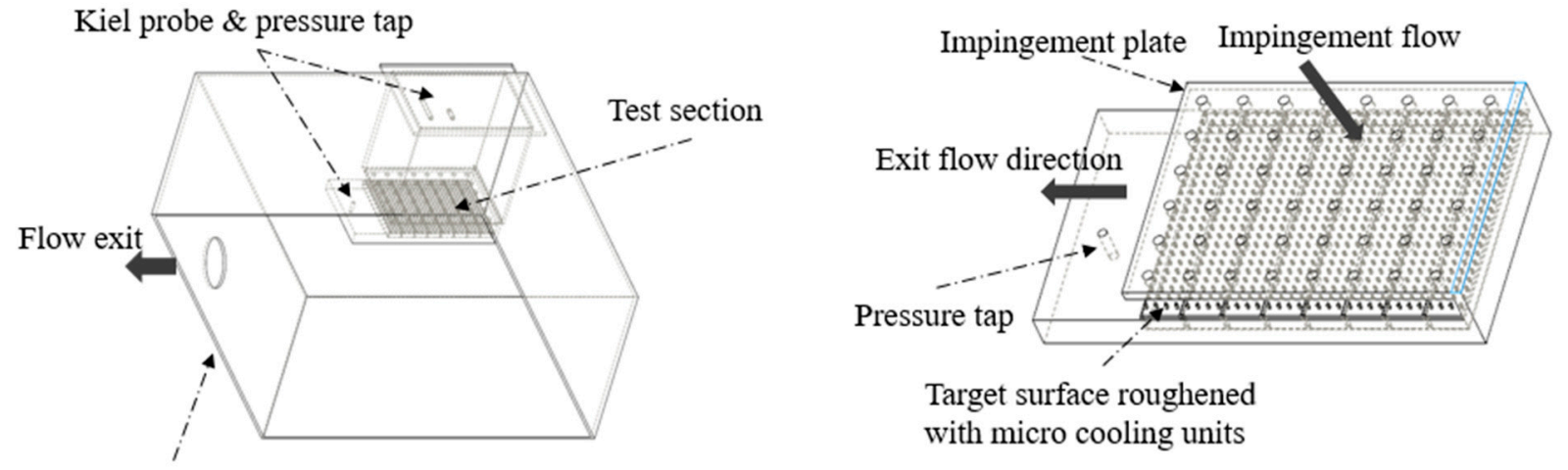

Negative pressure chamber

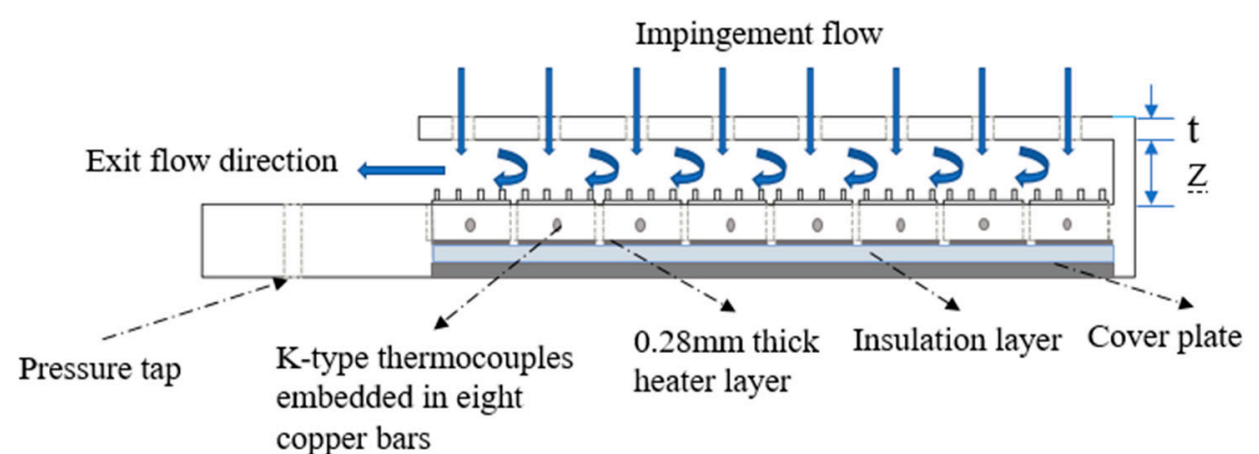

Figure 2. Diagram of test section.

Copper bar roughened with micro cooling units

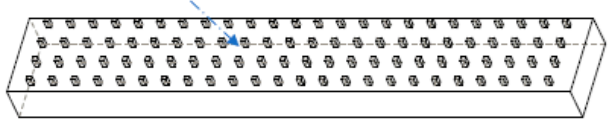

Micro cooling units patterns
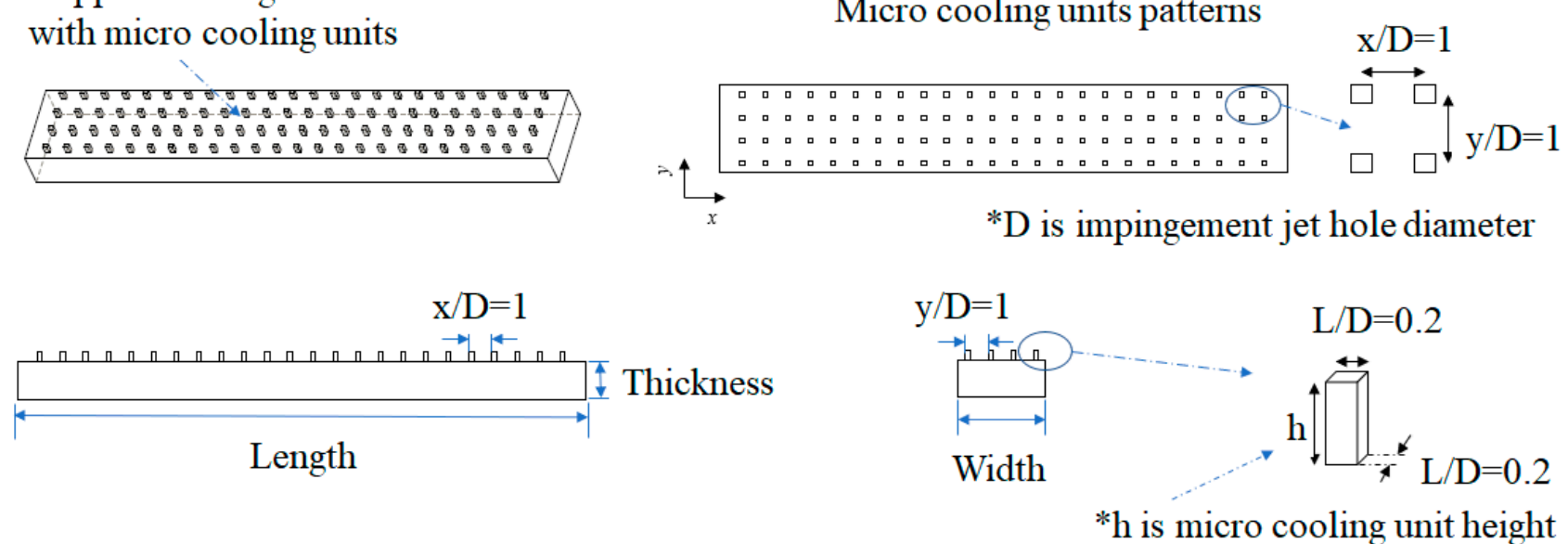

Figure 3. Copper bar with micro cooling units.

Table 1. Target surface micro cooling units configurations.

\begin{tabular}{cccc}
\hline Cases & Description & Pitch to Height Ratio & Wetted Area Ratio \\
\hline 1 & Baseline-Smooth & & 1.000 \\
2 & $0.01 \mathrm{D}$ & 100.0 & 1.075 \\
3 & $0.02 \mathrm{D}$ & 50.0 & 1.150 \\
4 & $0.05 \mathrm{D}$ & 20.0 & 1.375 \\
5 & $0.20 \mathrm{D}$ & 5.0 & 1.500 \\
6 & $0.40 \mathrm{D}$ & 2.5 & 2.000 \\
& (Micro cooling units height) & \\
\hline
\end{tabular}


Figure 4 also shows a schematic diagram of the impingement plate. Note that the impingent holes are inline, with 8 rows of holes in the streamwise direction and 6 holes in the spanwise direction. The hole spacing is $\mathrm{X} / \mathrm{D}=\mathrm{Y} / \mathrm{D}=4.0$ for both streamwise and spanwise directions. The jet-to-target surface distance is $\mathrm{Z} / \mathrm{D}=3.0 \mathrm{D}$. the impingement plate thickness is 1.0 D. Note that the impingement diameter $\mathrm{D}$ is $6.0 \mathrm{~mm}$.
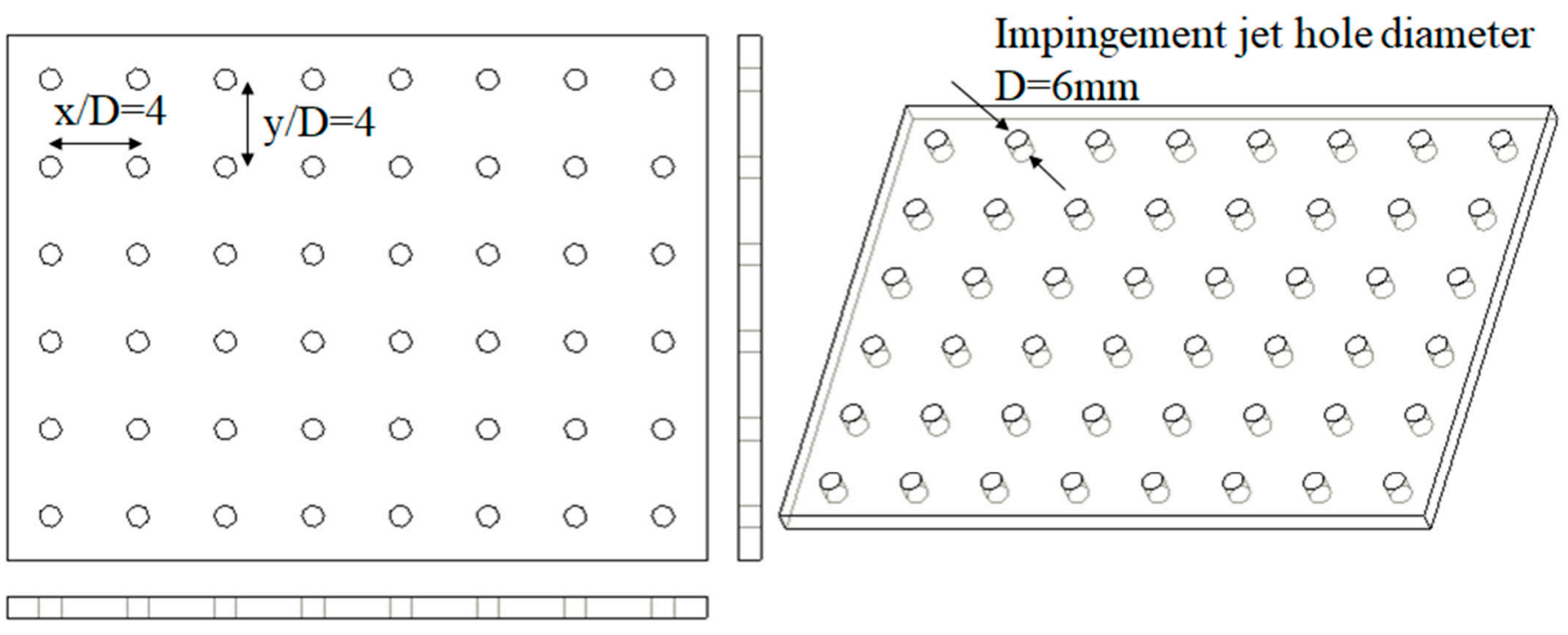

Figure 4. Diagram of impingement plate.

\subsection{Impingement Flow Conditions and Parameters Determination}

Local airflow mass flow rate is determined using the mass flow meter, denoted $\dot{m}$. The static density of the jet air is determined by the ideal gas law. Then, flow velocity and thermocouple measured recovery temperature are acquired, denoted as $V$ and $\mathrm{T}_{\mathrm{r}}$. Local static temperature $T_{S}$ is determined by

$$
\mathrm{T}_{\mathrm{s}}=\mathrm{T}_{\mathrm{r}}-\alpha \times\left(\frac{\mathrm{V}^{2}}{2 \mathrm{c}}\right)
$$

where $\alpha$ is the recovery factor. The associated value of $\alpha$ is 0.86 . The viscosity of the air is determined using Sutherland's formula [18]

$$
\mu=\mu_{0} \frac{T_{0}+C}{T_{s}+C}\left(\frac{T_{s}}{T_{0}}\right)^{3 / 2}
$$

where $C=120, T_{0}=291 \mathrm{~K}$, and $\mu_{0}=1.827 \times 10^{-5}$ Pa-s.

Then, the jet Reynolds number is determined by

$$
\mathrm{Re}=\frac{\rho \mathrm{uD}}{\mu}=\frac{4 \dot{\mathrm{m}}}{\mathrm{n} \pi \mathrm{D} \mu}
$$

where $\mathrm{n}$ is the number of impingement jet holes, and $\mathrm{D}$ is the impingement jet hole diameter.

\subsection{Discharge Coefficient Determination}

Stagnation pressure and static pressure are measured using Kiel probes and wall static pressure taps, respectively. Dynamic pressure is defined as the difference between static pressure and stagnation pressure. Kiel probes and pressure taps are carefully installed to minimize uncertainty. Pressure is acquired using STS127538/STS127539 differential pressure transducers and Agilent Keysight DAQ970A data acquisition system connected to a computer. 
The discharge coefficient $C_{d}$ is a common measurement to represent pressure loss of the flow system. Within the present investigation, $C_{d}$ is determined using

$$
\mathrm{C}_{\mathrm{d}}=\frac{\dot{\mathrm{m}}}{\mathrm{n} \rho \frac{\pi \mathrm{D}^{2}}{4}} \sqrt{\frac{\rho}{2 \Delta \mathrm{P}}}
$$

Within Equation (4), $\Delta \mathrm{P}$ is the pressure difference between the total pressure of the upper stream and the static pressure of downstream crossing the impingement plate. In the present investigation, the static pressure is acquired downstream of the test section were near the exit of the flow passage. The associated $C_{d}$ value represents pressure losses within the impingement flow passage, including pressure losses from surface distribution of micro cooling units arrangement.

\subsection{Heat Transfer Coefficient Measurement and Nusselt Number Measurement Approach}

Temperature measurements are made with calibrated thermocouples. Thermocouples are carefully installed and directed parallel to the airflow. Thermocouple signals are acquired and recorded at a rate of $10.0 \mathrm{~Hz}$ through three ART-DAM-3038 thermocouple input cards.

For different test flow conditions, copper bars need to be heated up by attached film heaters to an assigned temperature quickly, steadily, and accurately. As well, the heat flux of film heaters needs to be measured and determined precisely. A PID temperature control system is applied to determine the heat flux of each copper bar at different flow conditions. Within the arrangement, thermocouples measure and convert the temperature of copper bars into an electrical signal and then convert it into a Figure 5 signal through a DMA-3038 ART data acquisition module. The output Figure 6 signal is transferred and analyzed through an Arduino mega 2560 Microcontroller to compare with the assigned temperatures of copper bars, which is expected to heat up to by film heater attached to each of the copper bars. The difference between actual and assigned temperature results in a skew signal is then fed back to solid-state relay to control the voltage applied to the film heater to achieve the control of heat flux.

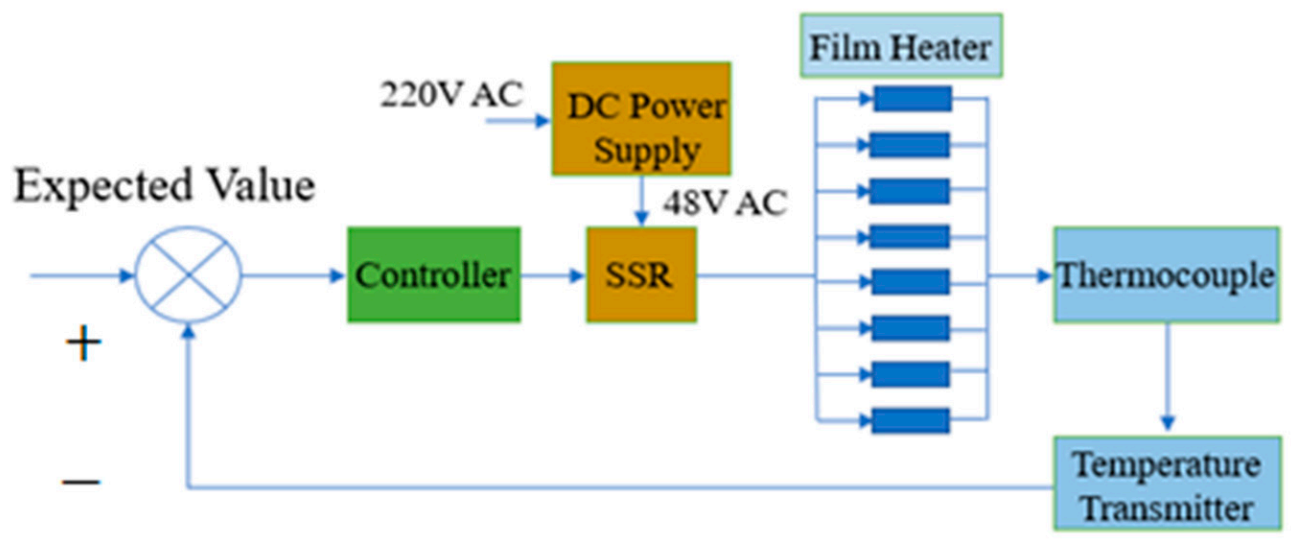

Figure 5. PID control system. 


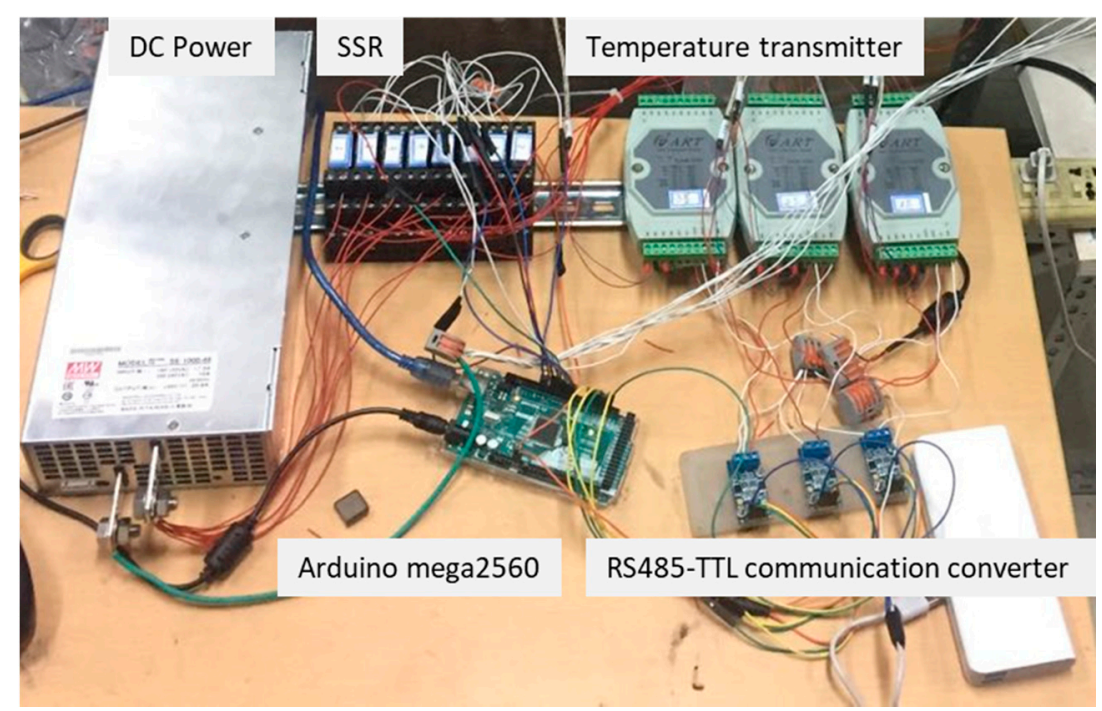

Figure 6. PID control system.

Within the present investigation, the procedures are described by Lu et al. [19]. For the present study, the copper bars that are used for the impingement target plate are with thermal conductivity of around $401 \mathrm{~W} / \mathrm{mK}$. In order to estimate and determine the uniformity of copper bar temperature in space, the Bi (Biot number) is introduced and given as follow

$$
\mathrm{Bi}=\frac{\mathrm{lh}}{\mathrm{k}}
$$

where $\mathrm{k}$ is thermal conductivity. $\mathrm{h}$ is the convective heat transfer coefficient. 1 is the characteristic length, which is commonly defined as the volume of the body divided by the surface area of the body;

For the present investigation, the associated Biot number with copper bar is significantly less than 0.1 . That represents the uniformity of temperature of each copper bar in space.

Next, the convective heat flux is determined by

$$
\mathrm{q}=\frac{\mathrm{V}^{2}}{\mathrm{RA}_{1}}-\mathrm{q}_{\text {loss }}
$$

where $\mathrm{R}$ and $\mathrm{V}$ are thin-film heater resistance and voltage, which are determined by digital multimeter and solid-state relay (SSR), respectively. $A_{1}$ is the area of the lower surface. The heat flux loss $\mathrm{q}_{\mathrm{loss}}$ is determined through one-dimensional thermal conduction analysis and finite element analysis. Within the present study, the associated $q_{l o s s}$ is less than $5.0 \%$.

The spatially averaged heat transfer coefficient is then given by

$$
\mathrm{h}=\frac{\mathrm{q}}{\left(\mathrm{T}_{\mathrm{w}}-\mathrm{T}_{\mathrm{f}}\right)}
$$

where $T_{f}$ and $T_{w}$ are jet supply passage stagnation temperature and copper bar surface temperature, respectively.

The spatially averaged Nusselt number is then determined by

$$
\overline{\overline{\mathrm{Nu}}}=\mathrm{hD} / \mathrm{k}
$$

\subsection{Experimental Uncertainty}

Experimental uncertainty using procedures described by Moffat [20], shown in Table 2. Note that heat transfer coefficient includes contributions related to heater voltage, heater resistance, the associated fluid temperature, and temperature of the copper bar. Within 
the present experiment, the uncertainty of the heater resistance and voltage are $0.8 \%$ and $1.2 \%$, respectively. The uncertainty of fluid temperature is about $\pm 0.1 \mathrm{~K}$. The experimental uncertainty of the associated temperature of copper bar is about $\pm 0.12 \mathrm{~K}$. The resulting experimental uncertainty of heat transfer coefficient is about $8.0 \%$, which is associated with experimental uncertainty of pressure drop and mass flow rate are $5.0 \%$ and $3.5 \%$, respectively.

Table 2. Experimental uncertainty magnitudes for the heat transfer coefficient and associated quantities to determine the heat transfer coefficient.

\begin{tabular}{cccccc}
\hline Quantity & Values & Error & htc & Copper Bar Number & Uncertainty \\
\hline $\mathrm{h}\left(\mathrm{W} / \mathrm{m}^{2} \mathrm{~K}\right)$ & & & 767 & 1 & $8.20 \%$ \\
$\mathrm{Vt}(\mathrm{V})$ & 200 & 2.4 & 22.3 & 2 & $7.20 \%$ \\
$\operatorname{Rt}(\Omega)$ & 310 & 2.5 & 14.9 & 3 & $6.70 \%$ \\
$\operatorname{Ri}(\Omega)$ & 38 & 0.307 & 7.4 & 4 & $6.60 \%$ \\
$\mathrm{qloss}\left(\mathrm{W} / \mathrm{m}^{2}\right)$ & 155 & 9.3 & 0.8 & 5 & $6.50 \%$ \\
$\mathrm{Tw}\left({ }^{\circ} \mathrm{C}\right)$ & 55 & 0.12 & 9.49 & 6 & $6.50 \%$ \\
$\mathrm{Tf}\left({ }^{\circ} \mathrm{C}\right)$ & 44 & 0.1 & 7.9 & 7 & $6.50 \%$ \\
Uncertainty $(\%)$ & & & 8.2 & 8 & $6.60 \%$ \\
\hline
\end{tabular}

\section{Results}

\subsection{Baseline Discharge Coefficient and Nusselt Number Comparisons}

Baseline discharge coefficient data for a smooth surface target plate from the present study are compared to values from Ren et al. [11] and Lee et al. [15] in Figure 7. Within Figure 8, spatially averaged Nusselt numbers for a baseline smooth surface target plate from the present study are compared to the data from the correlation equation by Florschuetz et al. [21]. In general, the present data show reasonable agreement with the reference date for both discharge coefficient and Nusselt number. Considering the $C_{d}$ comparison, the differences are due to different Re values and different jet-to-target plate distances and are denoted Z/D. For spatially averaged Nusselt number, the comparison shows a maximum deviation of approximately $7 \%$.

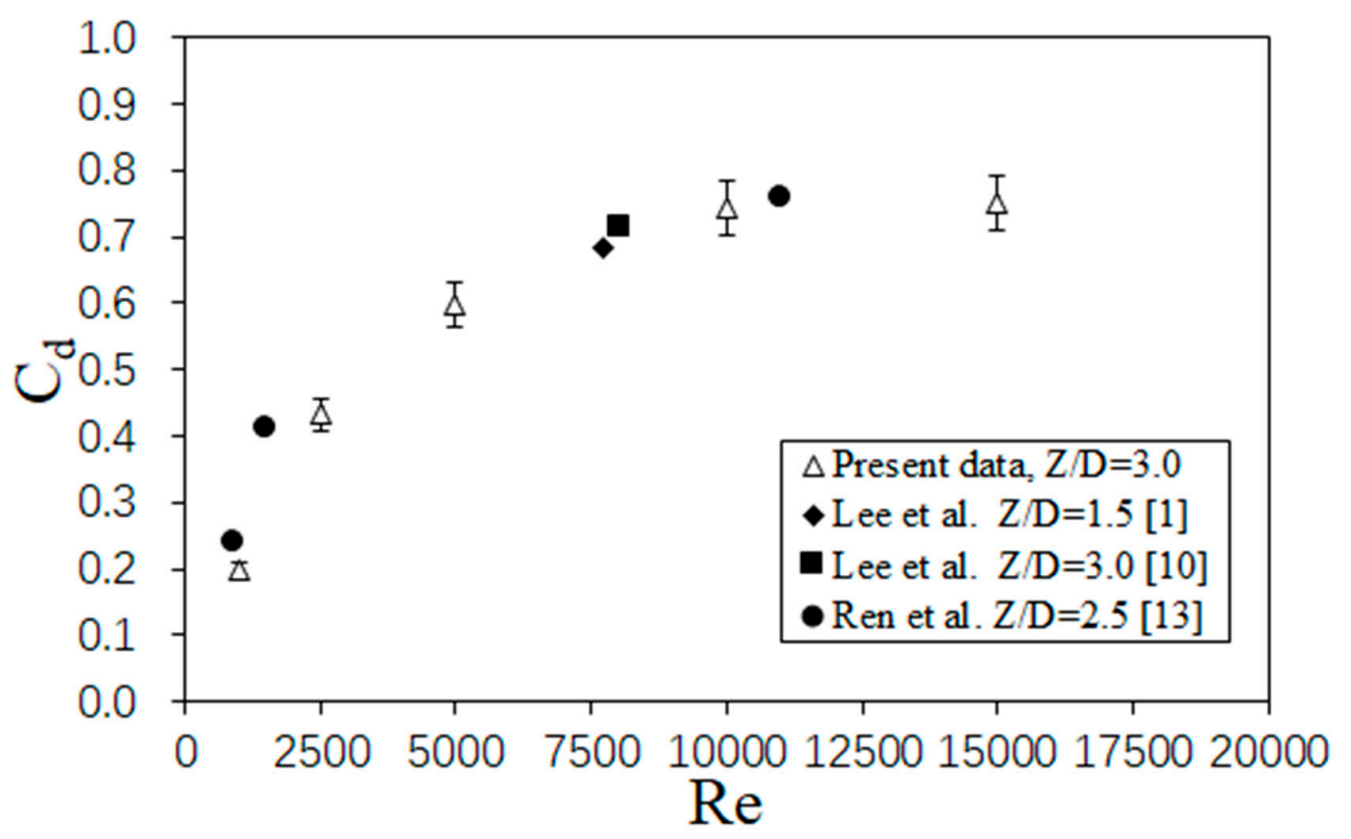

Figure 7. Discharge coefficient variation as dependent upon $R e$, including comparisons with Lee et al. [1,10] and Ren et al. [13]. 


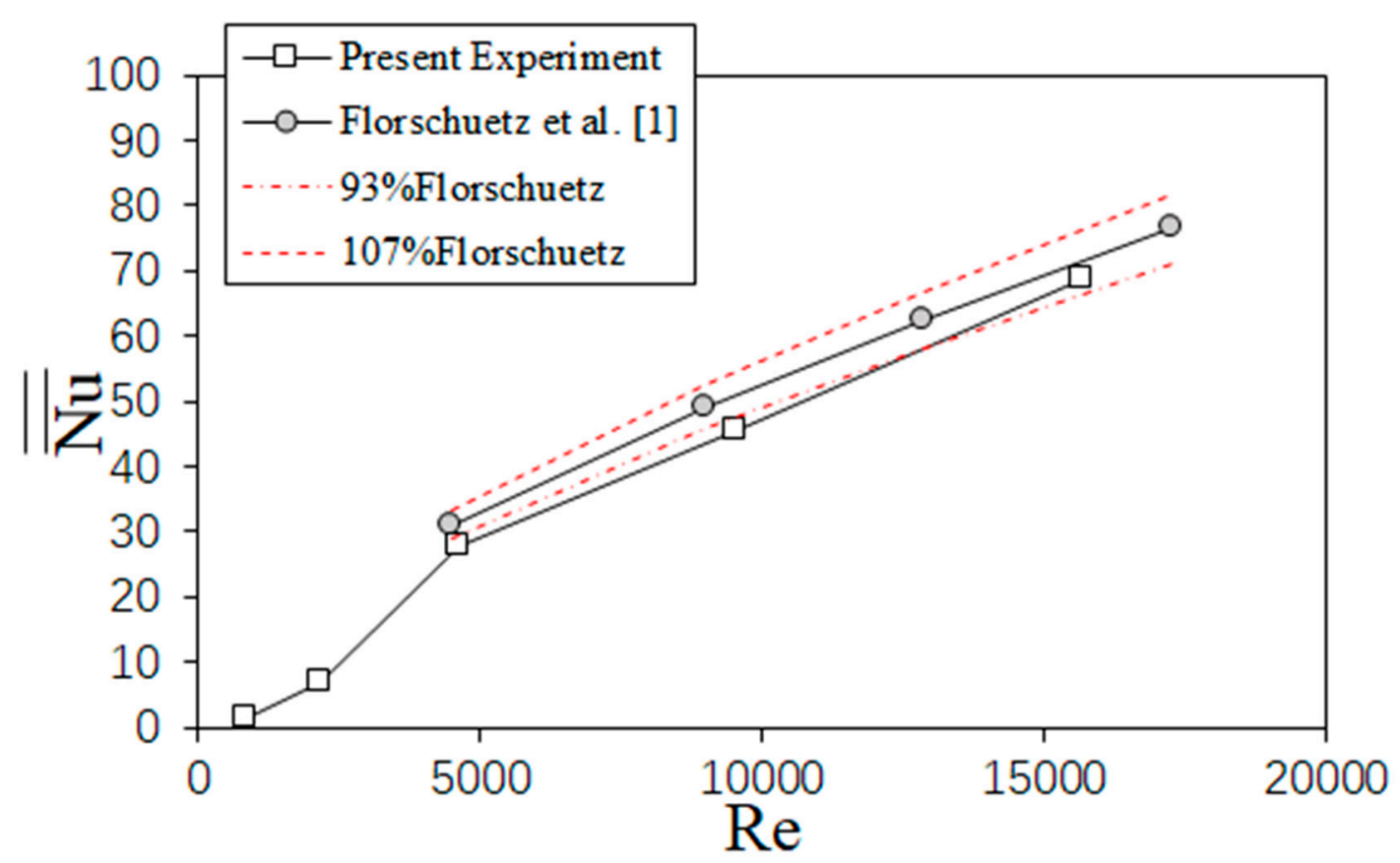

Figure 8. Spatially averaged Nusselt numbers as dependent upon Re, including comparison with impingement jet array correlation from Florschuetz et al. [21].

\subsection{Discharge Coefficient Variations}

Figures 9-11 show the discharge coefficient data variation with different ranges of $\mathrm{Re}_{\mathrm{j}}$ for different micro cooling units heights. Note that dash lines are presented a deviation of $5 \%$ uncertainty for $C_{d} / C_{d 0}=1$ (unity). In Figure 11 , light green and light orange areas represent pressure loss reduction region and pressure loss increasing region, respectively.

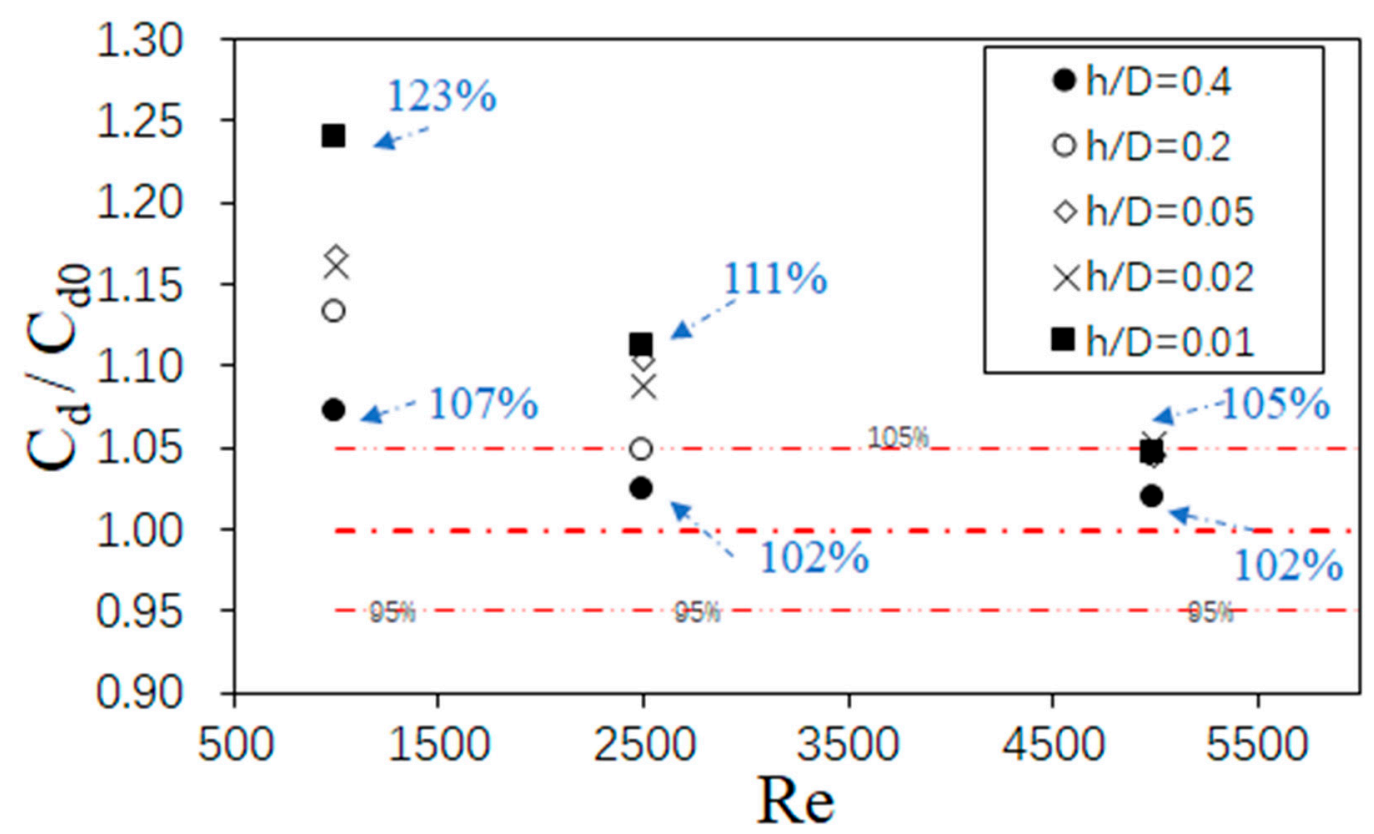

Figure 9. Discharge coefficient ratio as dependent upon $\mathrm{Re}_{\mathrm{j}}$ ranging from 1000 to 5000 for different micro cooling units heights. 


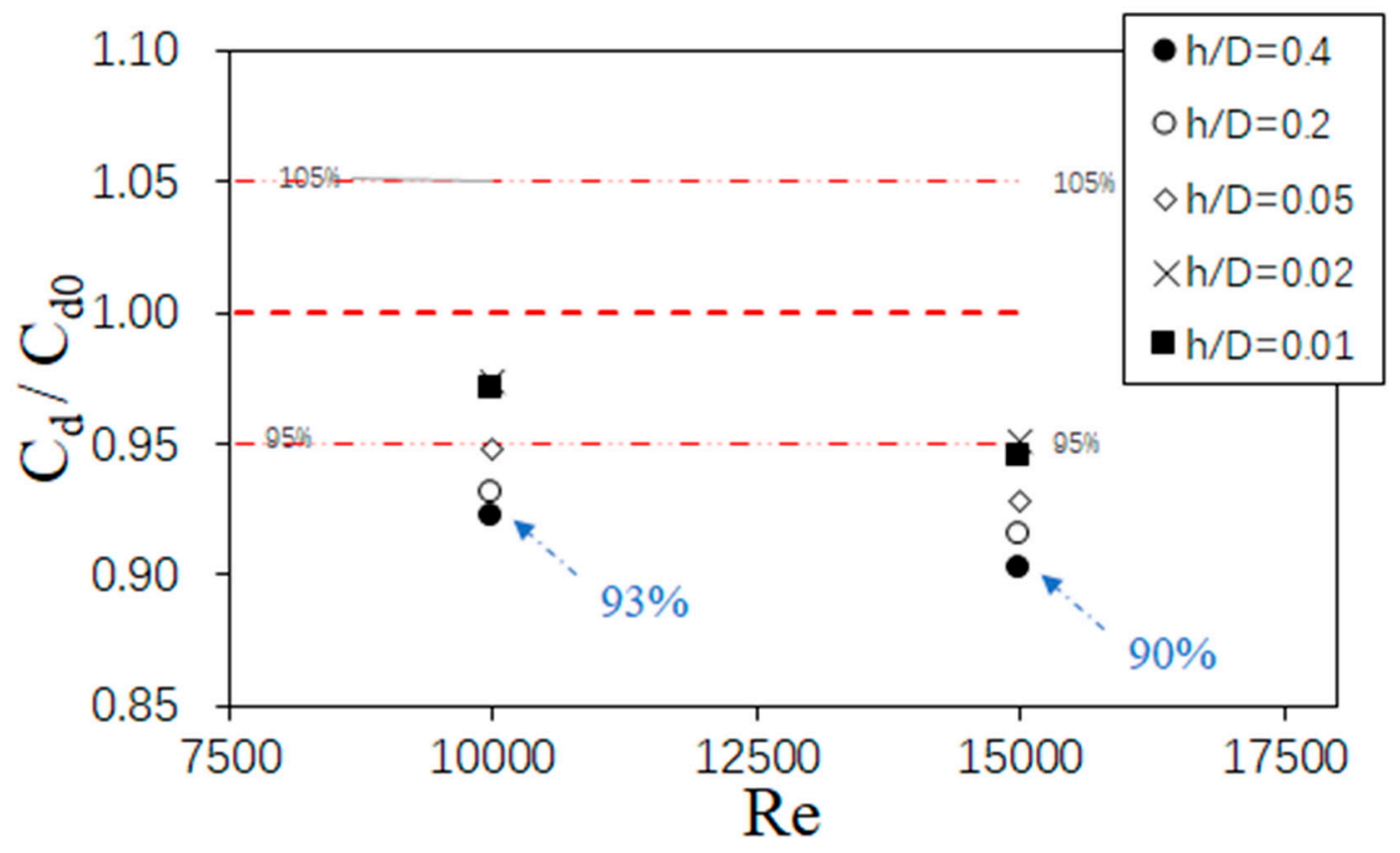

Figure 10. Discharge coefficient ratio as dependent upon $\mathrm{Re}_{\mathrm{j}}$ ranging from 7500 to 15,000 for different micro cooling units heights.

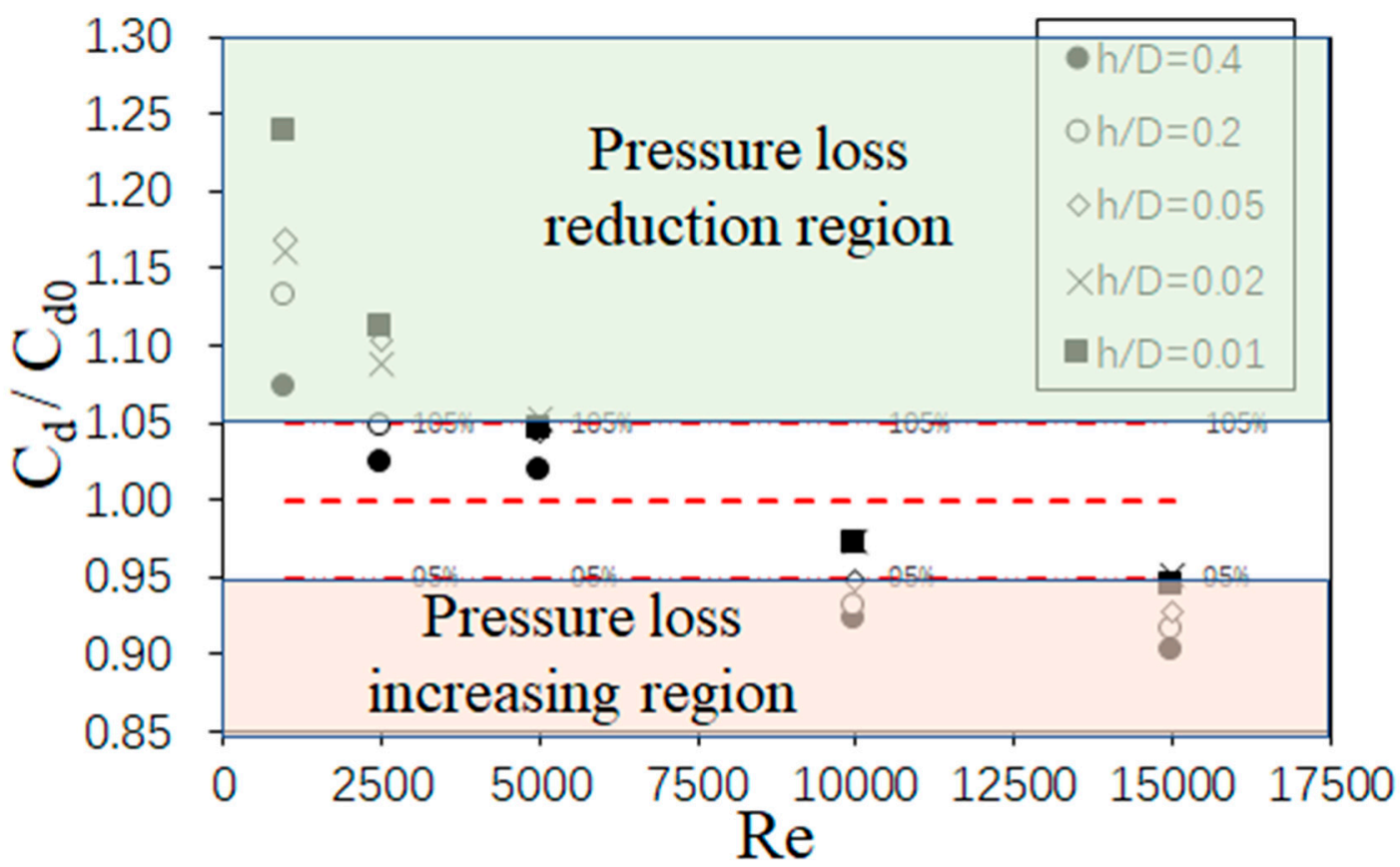

Figure 11. Discharge coefficient ratio as dependent upon $\mathrm{Re}_{\mathrm{j}}$ ranging from 0 to 15,000 for different micro cooling units heights.

Figure 9 shows the discharge coefficient data variation with impingement jet Reynolds number ranging from 1000 to 5000 for different micro cooling units heights. When compared at a range of $\operatorname{Re}_{j}=1000$ to 5000 , discharge coefficient ratio variations are approximately $107 \%$ to $123 \%\left(\operatorname{Re}_{j}=1000\right), 102 \%$ to $111 \%\left(\operatorname{Re}_{j}=2500\right)$, and $102 \%$ to $105 \%\left(\operatorname{Re}_{j}=5000\right)$, for each of micro cooling units height examined, yielding about 2 18\% reductions in pressure losses for the system.

The discharge coefficient data variation with impingement jet Reynolds numbers of 10,000 and 15,000 for different micro cooling units heights are presented in Figure 10. When 
compared at $\operatorname{Re}_{j}=10,000$ and 15,000, discharge coefficient ratio values result in maximum values of $2 \%$ and $5 \%$ increasing in pressure losses for the system, respectively. In Figure 11 , it should be noticed that when compared at particular values of $\operatorname{Re}_{j}$, discharge coefficient ratio values decrease as micro cooling units height increases, which indicates that target plate with a higher micro cooling units height causes greater pressure losses for the system. This is because that the increasing height of the micro cooling units results in the increase in associated generated drag. In addition, note that the using of the cooling unit elements do not increase discernably in pressure loss penalty for the system for all the test configuration examined. Such behavior results from the pitch-to-height ratio of micro cooling units elements on the target plate surface. The pitch-to-height ratio is commonly defined as the adjacent spacing of cooling units elements divided by the height of the element. Within the present study, the micro cooling units elements are designed at four pitch-to-height ratios: 2.5, 5, 20, 50, and 100 (as listed in Table 1). When pitch-to-height ratios are 2.5 and 5, the micro cooling unit elements are arranged into a low pitch-to-height ratio arrangement along the target surface, which approaches to be a smooth target surface. As a result, lower flow mixing and less momentum and energy exchange are present. When the micro cooling units elements are arranged into less dense patterns (as pitch-to-height ratio values of 20, 50, and 100), a near-wall viscous sublayer is destroyed when fluid passes by the elements, then recirculates downstream of elements, and then successfully reforms and develops between adjacent elements.

\subsection{Effects of Reynolds Number}

Figures 12-17 show spatially averaged Nusselt number results for different $\mathrm{Re}_{\mathrm{j}}$ ranging of 1000 15,000 and different micro cooling units height of 0.01 0.4 D. Each spatially averaged value is determined over an area that extends over an $x / D$ range relative to each streamwise row location and over a $\mathrm{y} / \mathrm{D}$ range, comprised of a complete period of local streamwise and spanwise Nusselt number variation. For all cases considered, note that spatially averaged Nusselt number increases with $\mathrm{Re}_{\mathrm{j}}$ because of larger flow speeds and increased magnitudes of advection. In addition, note that Figures 12-17 show a qualitatively similar variation of spatially averaged Nusselt number with streamwise row location when different micro cooling units heights are compared at similar impingement jet Reynolds number.

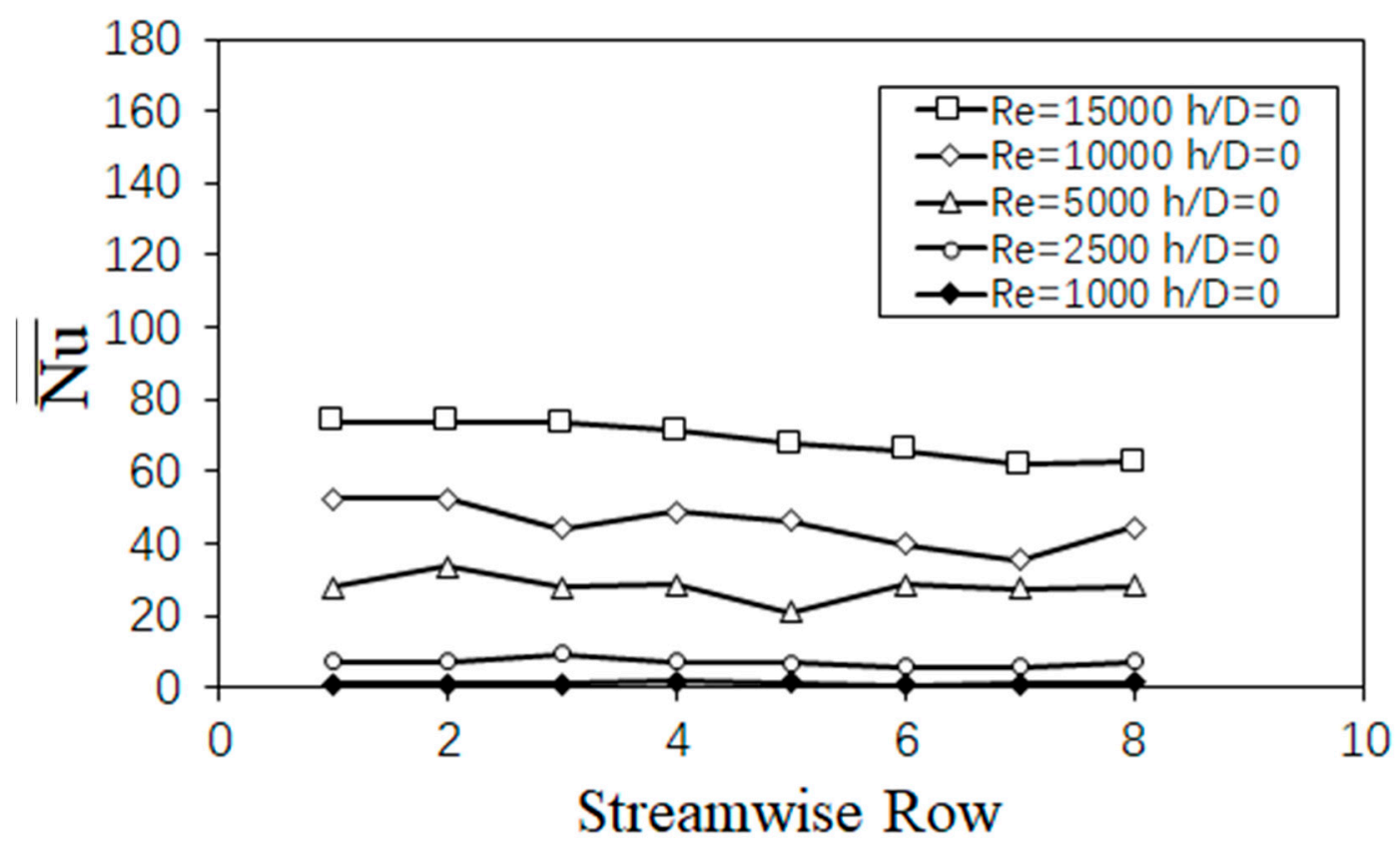

Figure 12. Spatially averaged Nusselt numbers as dependent upon streamwise row location, for different $\mathrm{Re}_{\mathrm{j}}$, for smooth surface target plate. 


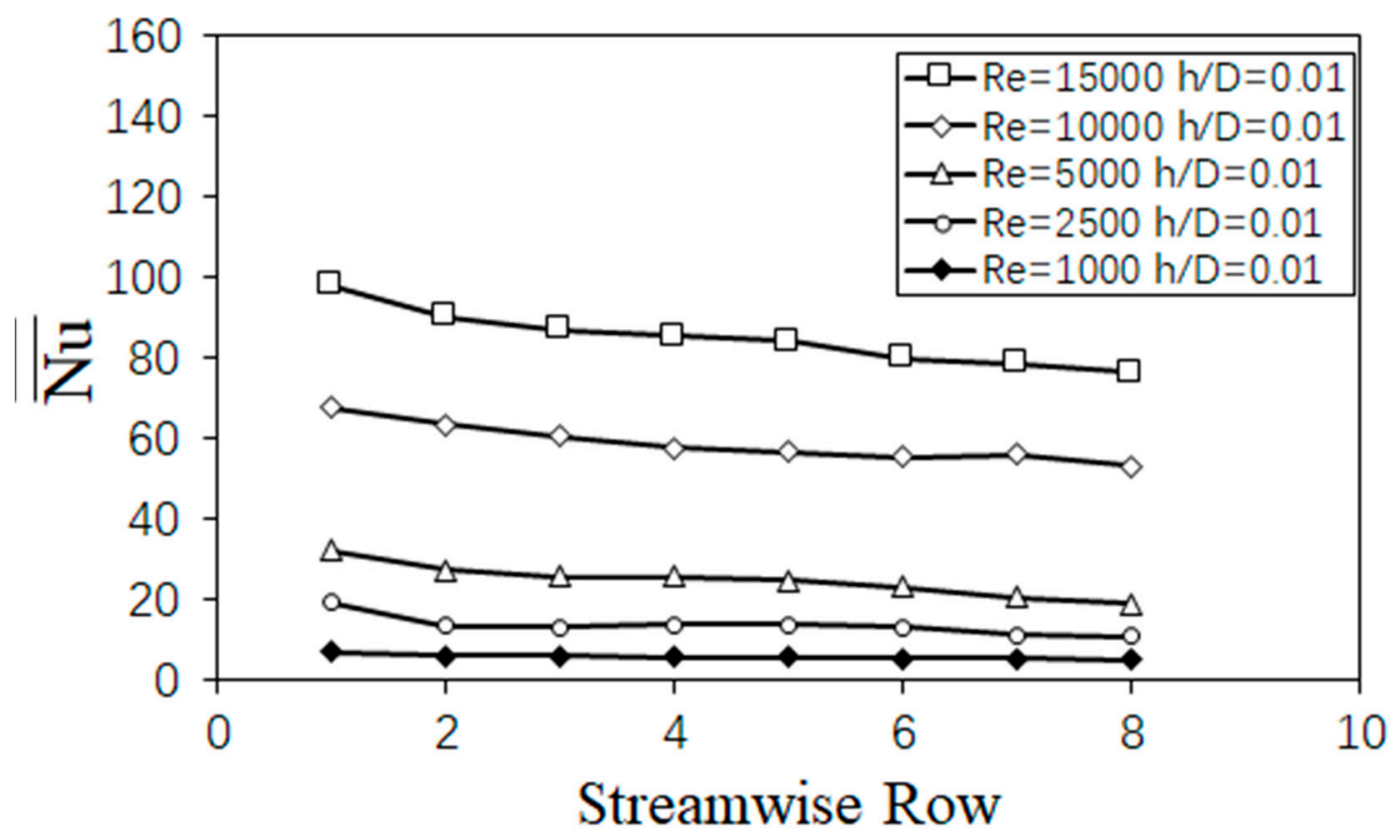

Figure 13. Spatially averaged Nusselt numbers as dependent upon streamwise row location, for different $\mathrm{Re}_{\mathrm{j}}$, for micro cooling units height of $0.01 \mathrm{D}$.

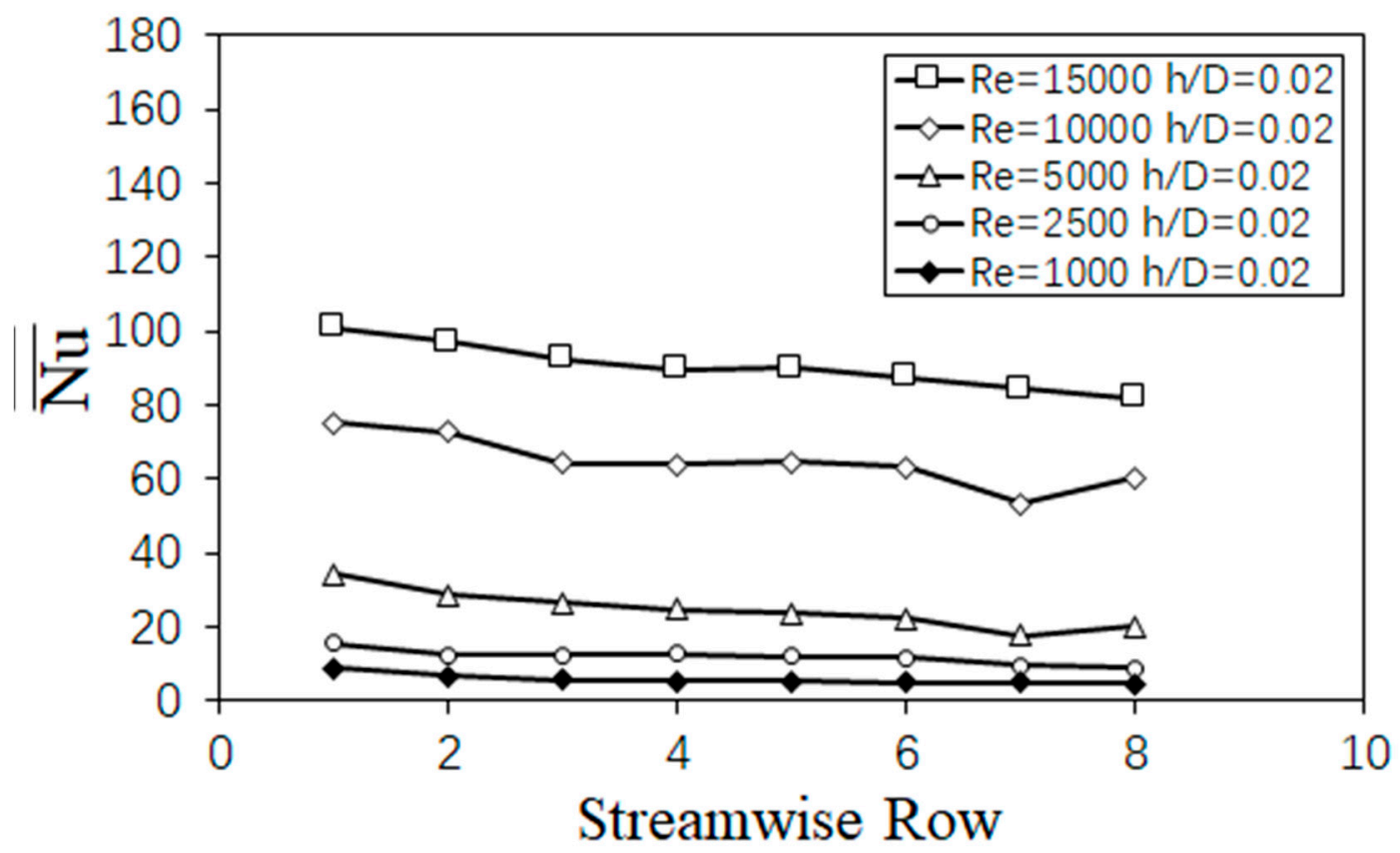

Figure 14. Spatially averaged Nusselt numbers as dependent upon streamwise row location, for different $\mathrm{Re}_{\mathrm{j}}$, for micro cooling units height of $0.02 \mathrm{D}$. 


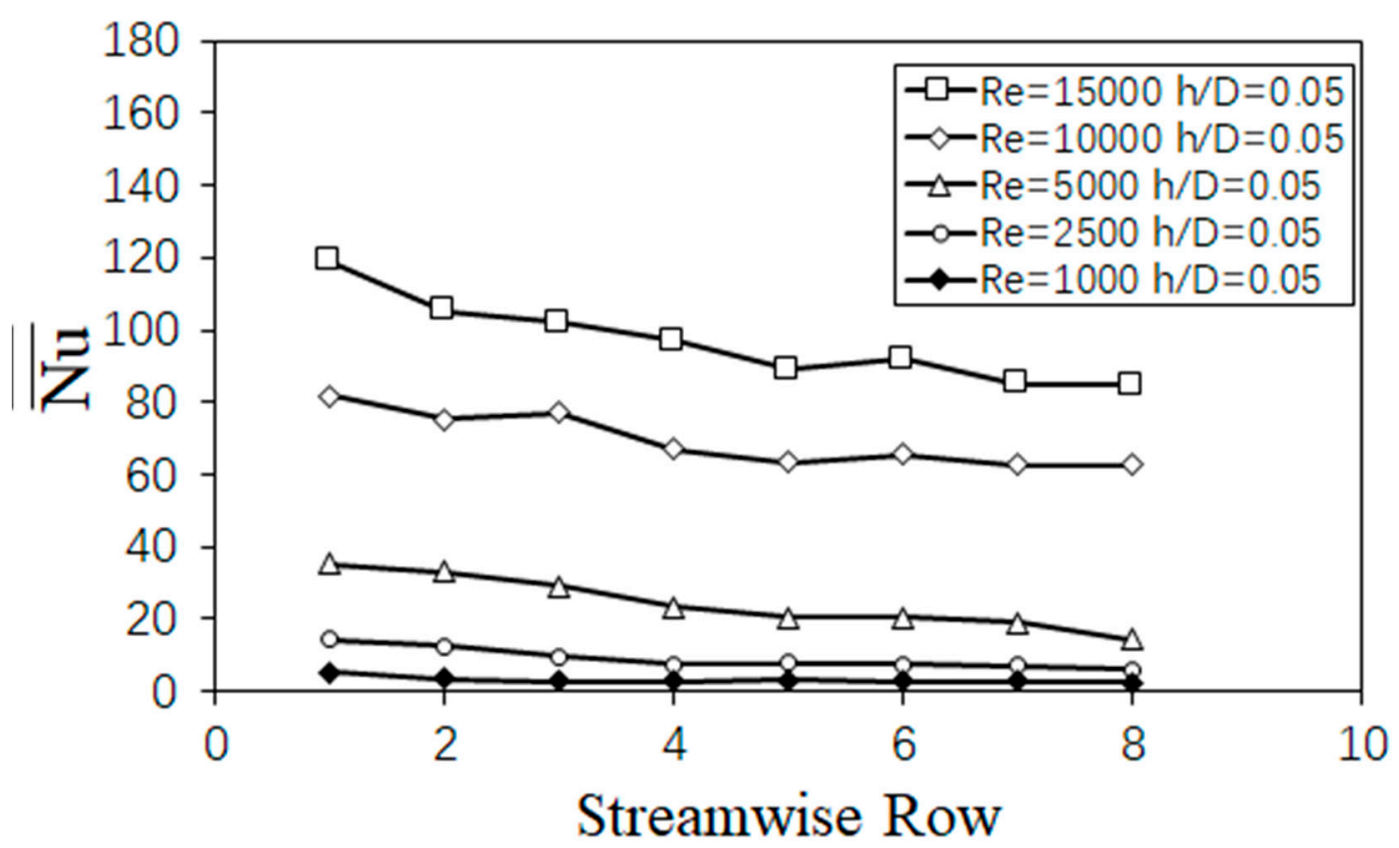

Figure 15. Spatially averaged Nusselt numbers as dependent upon streamwise row location, for different $\mathrm{Re}_{\mathrm{j}}$, for micro cooling units height of $0.05 \mathrm{D}$.

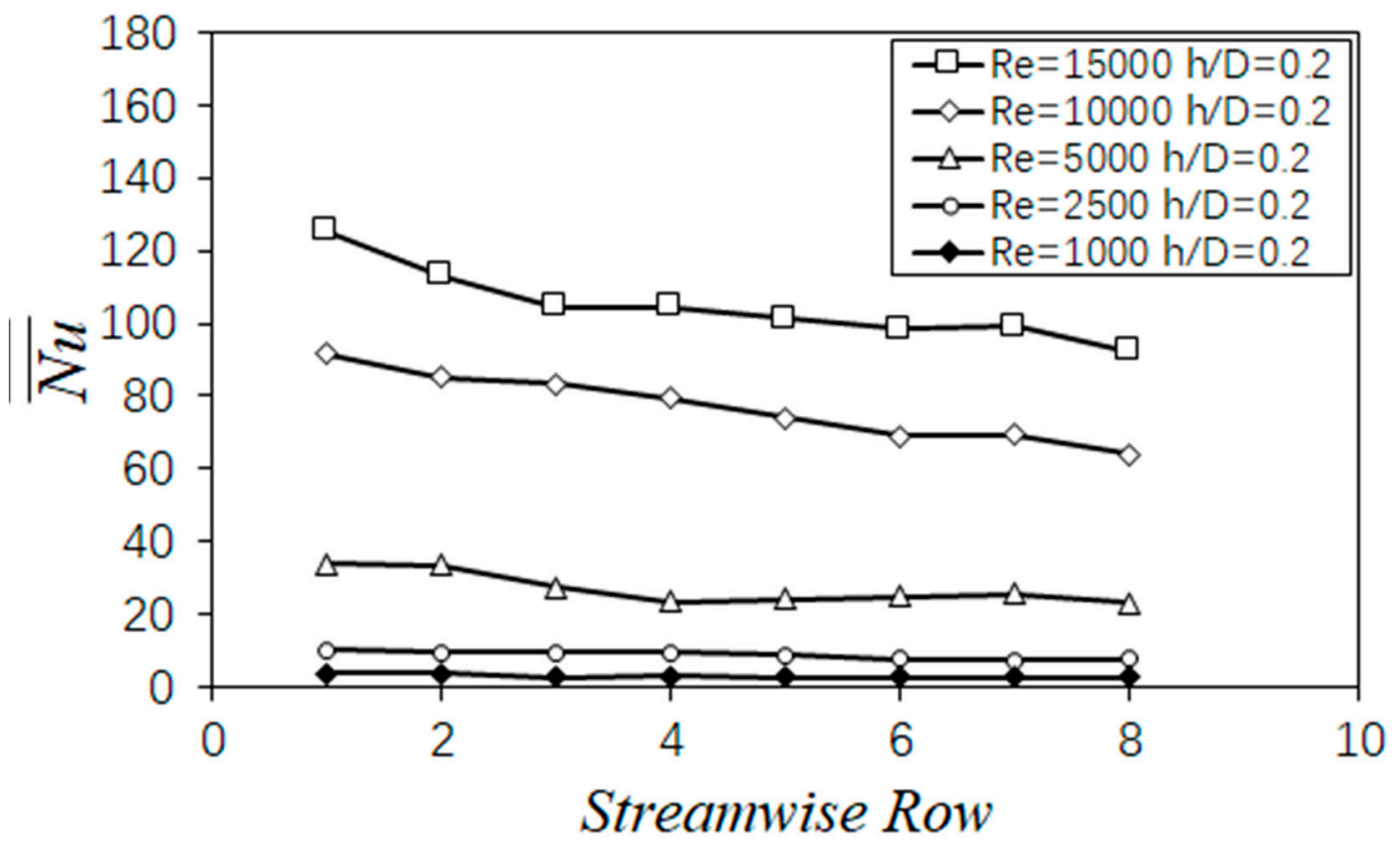

Figure 16. Spatially averaged Nusselt numbers as dependent on streamwise row location, for different $\mathrm{Re}_{\mathrm{j}}$, for micro cooling units height of $0.2 \mathrm{D}$. 


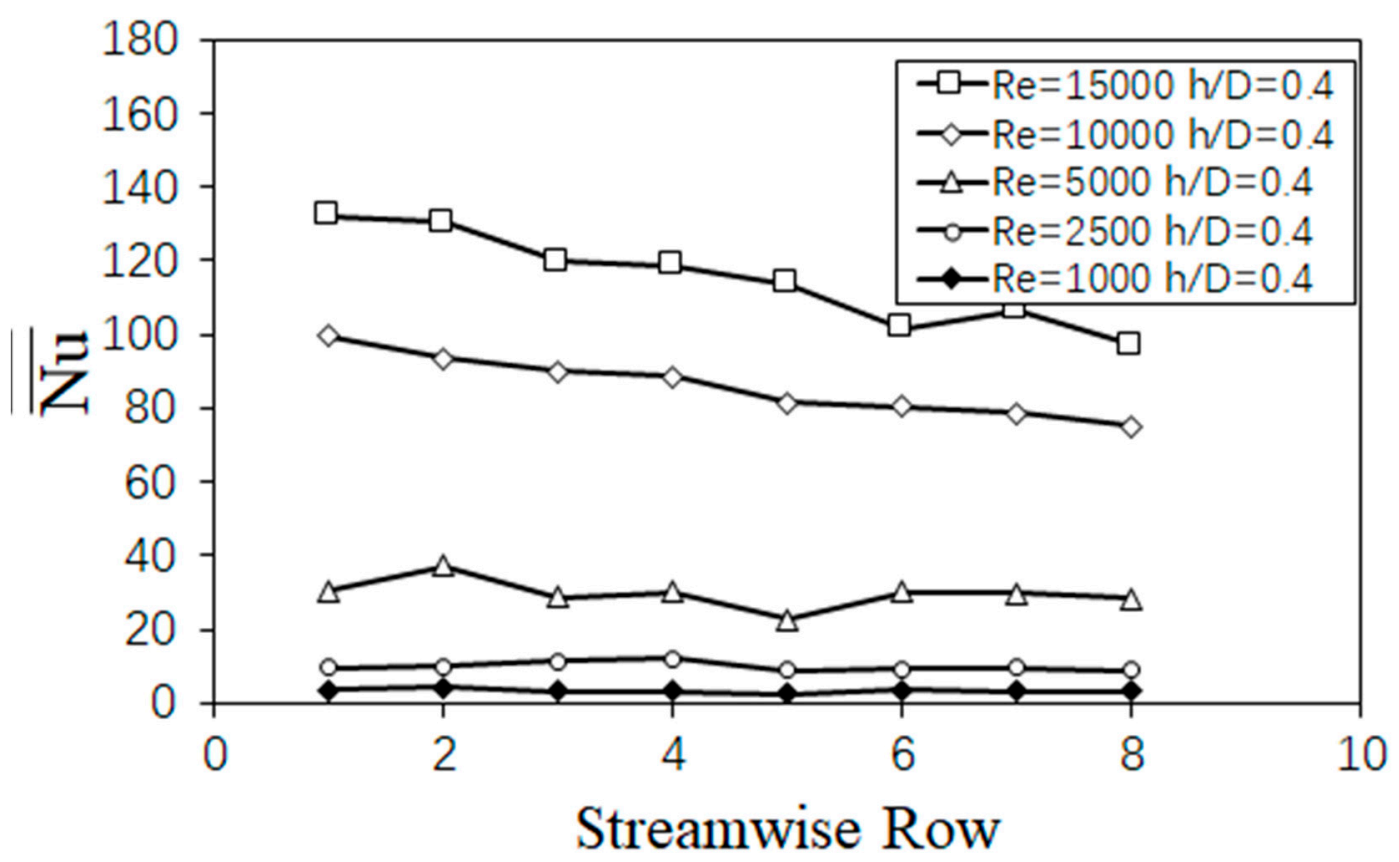

Figure 17. Spatially averaged Nusselt numbers as dependent on streamwise row location, for different $\mathrm{Re}_{\mathrm{j}}$, for micro cooling units height of $0.4 \mathrm{D}$.

\subsection{Effects of Micro Cooling Units Height}

Figures 18 and 19 show spatially averaged Nusselt number ratios. The baseline Nusselt numbers used for normalization of these results are obtained of an experimental condition with impingement cooling air applied to smooth surface target plate. Here, jet-to-target plate distance $Z / D=3$ and impingement jet Reynolds numbers are 10,000 and 15,000 . When compared at a particular streamwise location and impingement jet Reynolds number value, spatially averaged Nusselt number ratios generally increase as micro cooling units height increases. In Figures 18 and 19, it shows an approximate heat transfer augmentation of 20\% to $120 \%$. Such augmentation is due to increased thermal transport and near-wall mixing, as the cooling unit elements are higher. It is believed that the micro cooling units along the wall break the viscous sublayer, which is normally formed within the boundary layer on the smooth target surface. 


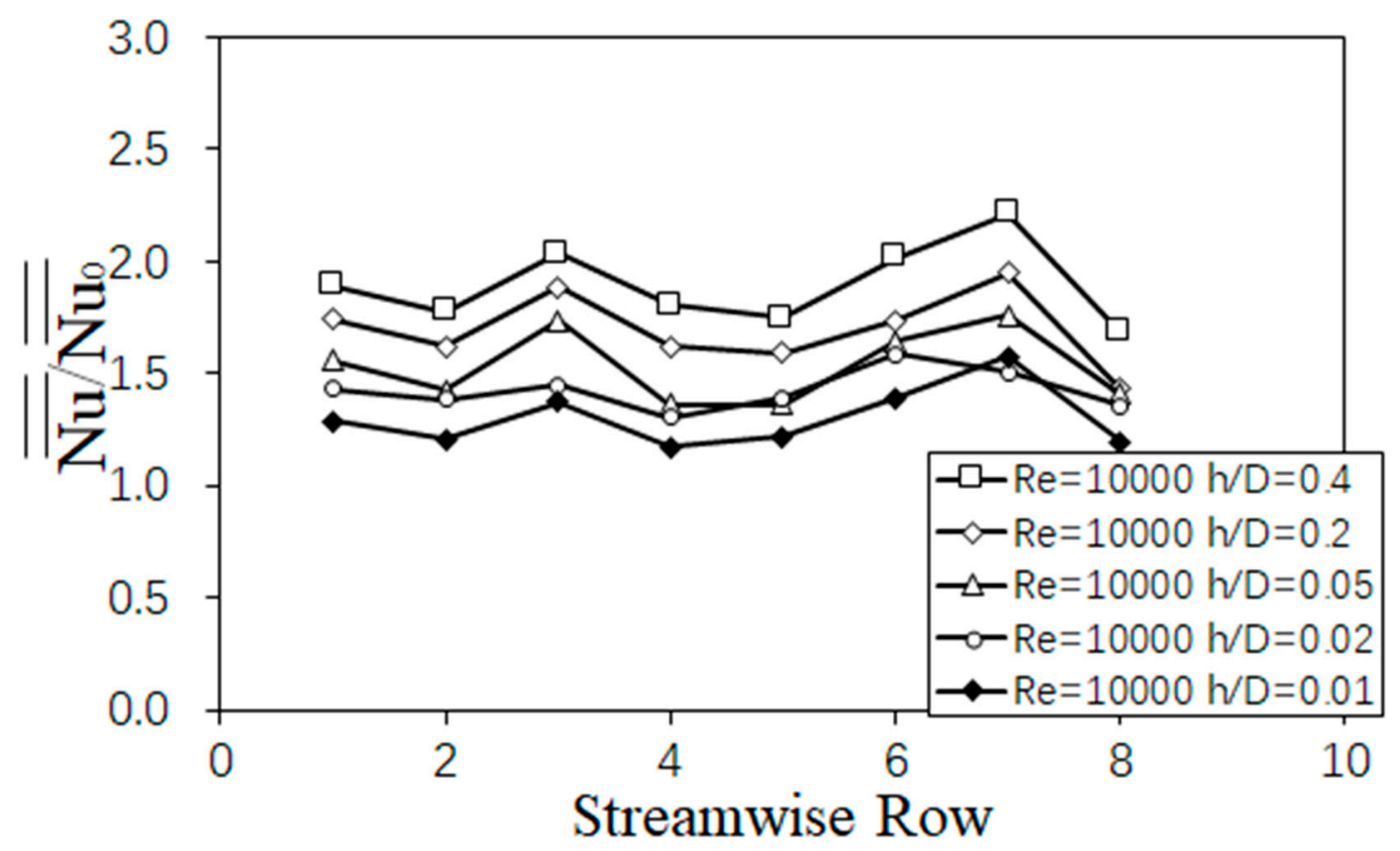

Figure 18. Spatially averaged Nusselt number ratios as dependent on streamwise row location, for micro cooling units height, for $\operatorname{Re}_{\mathrm{j}}=10,000$.

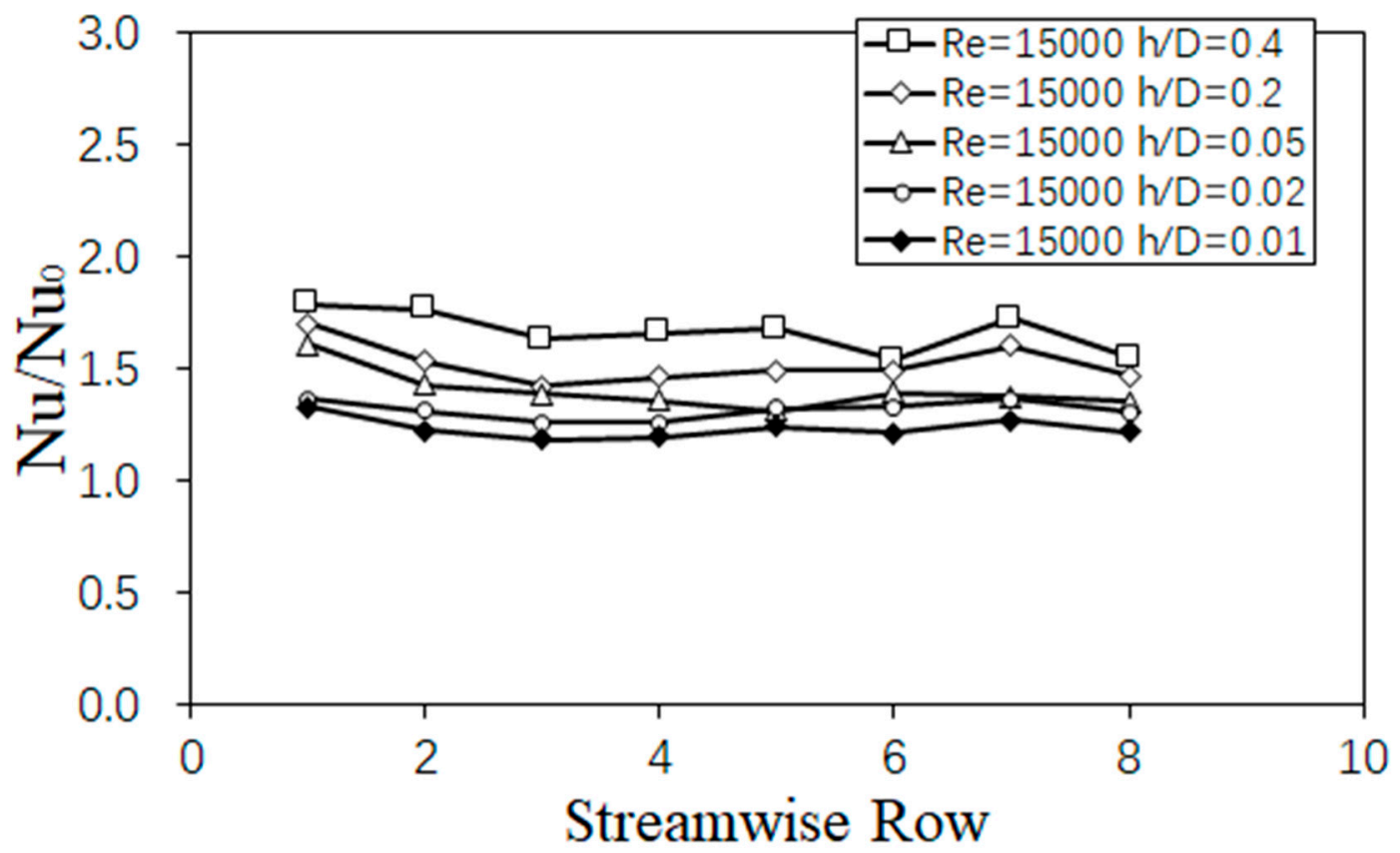

Figure 19. Spatially averaged Nusselt number ratios as dependent on streamwise row location, for micro cooling units height, for $\operatorname{Re}_{j}=15,000$.

\subsection{Effects of Wetted Area Ratio}

Figure 20 shows spatially averaged Nusselt number ratios as based upon wetted area ratio, for different $\mathrm{Re}_{\mathrm{j}}$ ranging from 1000 to 15,000 , for different micro cooling units height of $\mathrm{h} / \mathrm{D}=0.01,0.02,0.05,0.2$, and 0.4 . Here, the wetted surface area is defined as the total area of the surface that is adjacent to the flow. The dashed line represents the increase in spatially averaged Nusselt number as a contribution of the increased wetted area ratio. The wetted area ratio values are shown in Table 1 for all cases examined. 


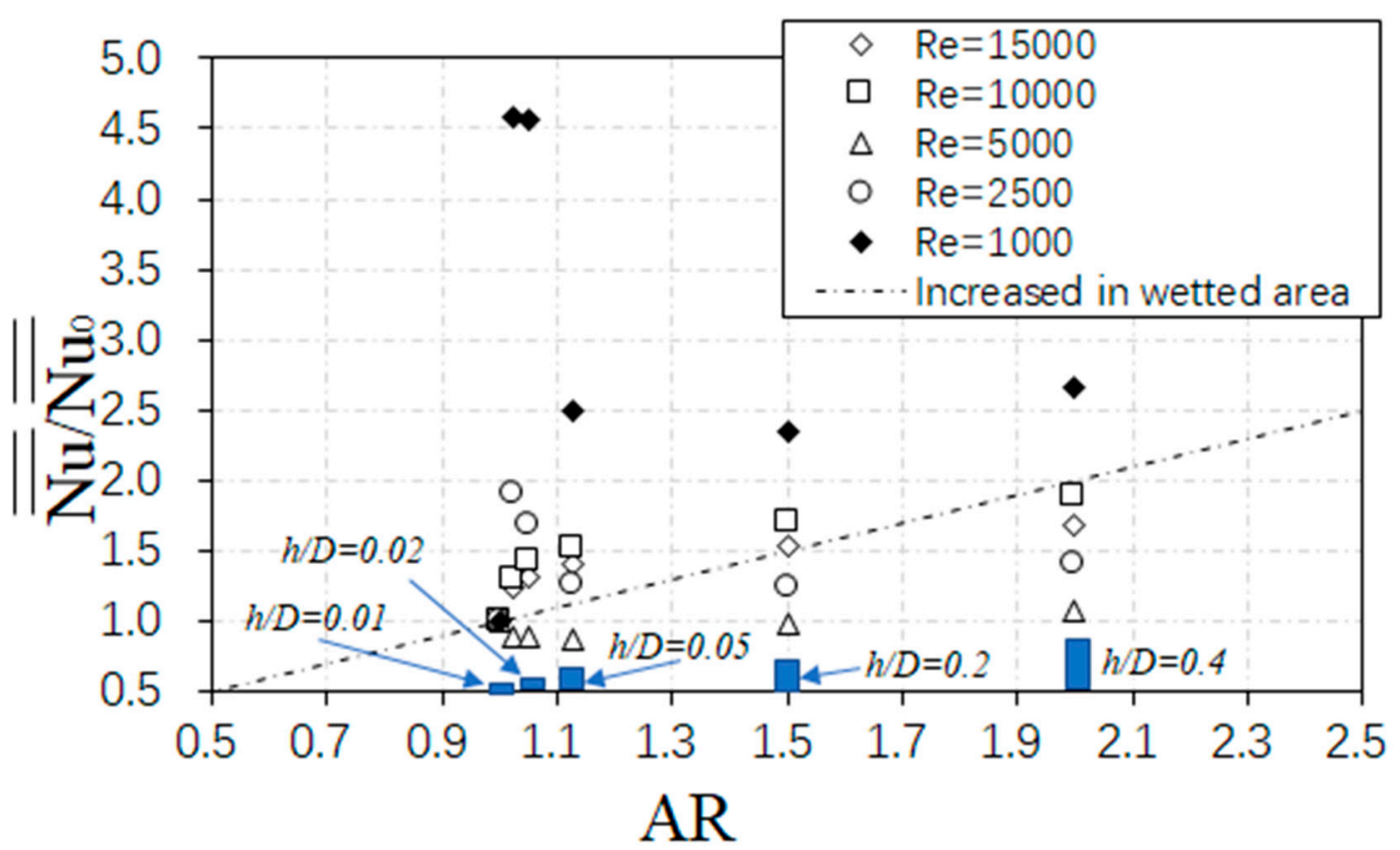

Figure 20. Spatially averaged Nusselt number ratios as dependent upon wetted area ratio, for different micro cooling units height, and different $\mathrm{Re}_{\mathrm{j}}$.

In Figure 20, in general, considering spatially averaged Nusselt number ratio values are above the dashed line, data show an approximate $20-300 \%$ augmentation for tested configurations. It is believed that the arrays of micro cooling units along the surface increasing the local near-wall turbulent and the turbulent mixing. [22]. For these data drops below the dashed line, such behavior is due to two effects. The first is that flow phenomena that local flow separation and recirculation occurs downstream of the micro cooling element, which decreases both local thermal transport and the associated heat transfer. The second is because the added micro cooling units bring in extra thermal conduction resistance [22].

\subsection{Spatially Averaged Nusselt Number Variations}

Figure 21 shows the spatially averaged Nusselt numbers variations with discharge coefficient for different cooling units height $\mathrm{h}$ and $\mathrm{Re}_{\mathrm{j}}$. Figure 22 shows the spatially averaged Nusselt number ratios variations with discharge coefficient ratio for different cooling units height $h$ and $\mathrm{Re}_{\mathrm{j}}$. These data are presented because of the two important key evaluations of internal cooling technology development in the gas turbine industry. One is heat transfer level enhancement, and the other is the pressure drop penalty. The present study shows that tested configurations provide an approximate $20-300 \%$ heat transfer augmentation when compared to the smooth target surface. Associated pressure drop penalty shows a variation of $-10 \%$ to $+20 \%$ in magnitude compared to values of the smooth target surface. With such characteristics, it is indicated that the impingement jet array combined with roughened target surface shows marvelous ability in improving overall cooling performance for technological advancement, especially benefiting by the advanced additive manufacturing, which highly expands the used micro cooling unit elements in different applications. 


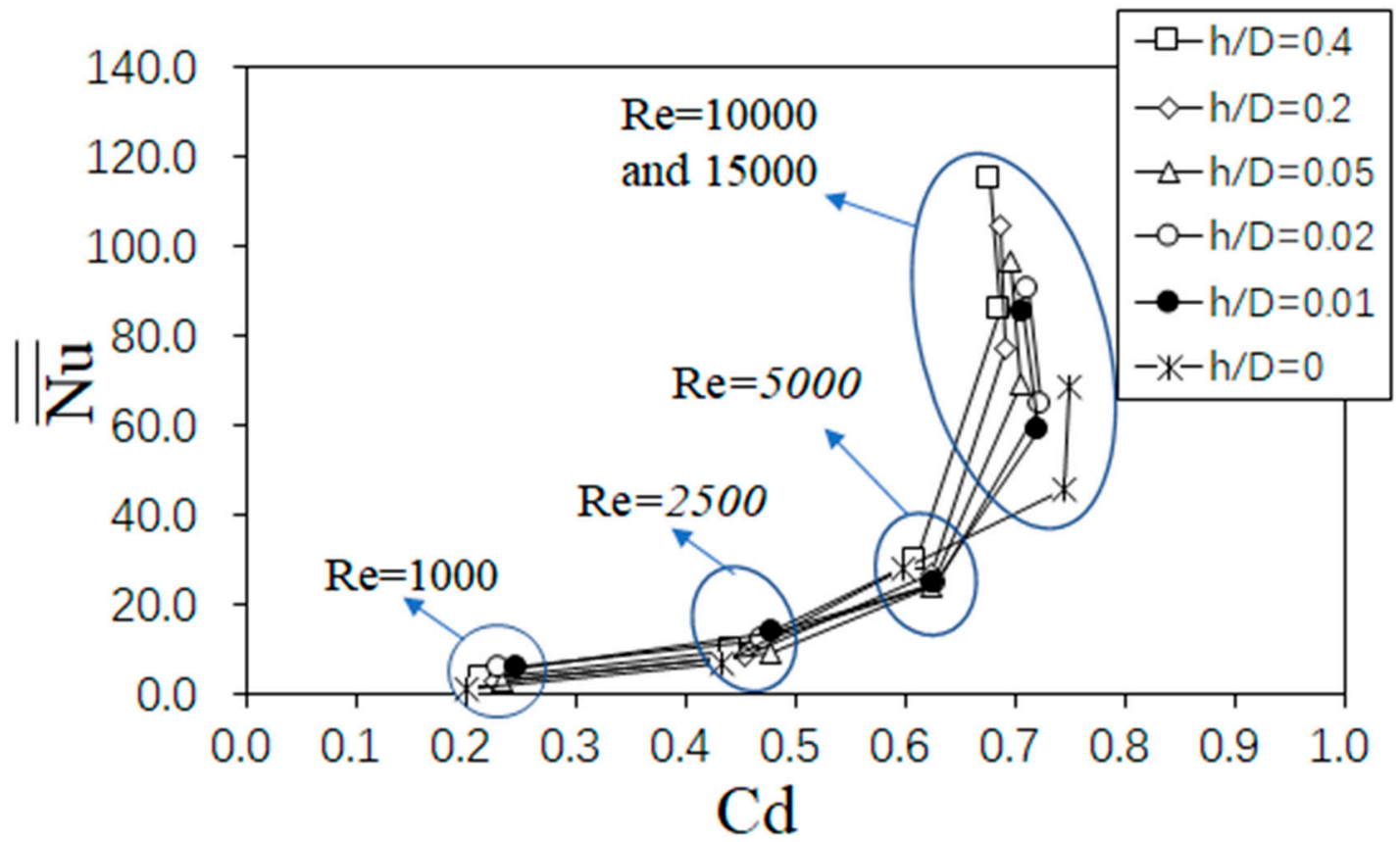

Figure 21. Spatially averaged Nusselt number as dependent upon $C_{d}$, for different micro cooling unit heights, and different $\operatorname{Re}_{j}$.

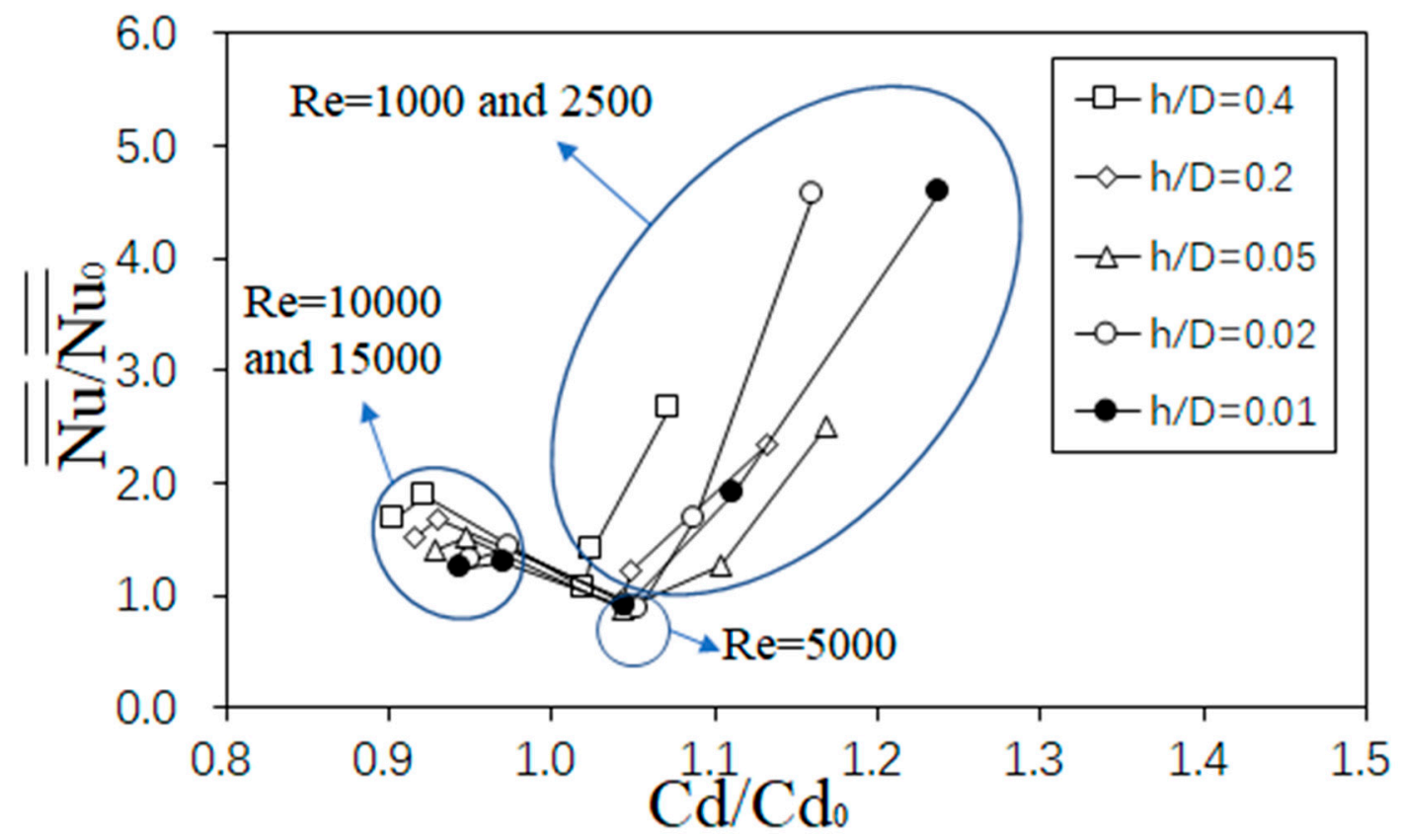

Figure 22. Spatially averaged Nusselt number ratios as dependent upon discharge coefficient ratio, for different micro cooling unit heights, and different $\mathrm{Re}_{\mathrm{j}}$.

\subsection{Discharge Coefficient Ratio Correlation Determination}

As mentioned previously, pressure drop penalty is a key parameter in evaluating heat transfer characteristics of technology in the gas turbine industry. Efforts are made to generate a correlation for target surface installed with micro cooling units of different cooling units elements height. According to the present investigation, a correlation for discharge coefficient ratio $C_{d} / C_{d 0}$ is given in Equation (9). Note that this correlation is determined based upon impingement cooling configuration and micro cooling units 
type shown in Figure 4 and Table 1, respectively. In addition, note that a linear approach is generated as dependent upon the variable (denoted as G), which is associated with the micro cooling units height and skin friction coefficient. Figure 23 show comparison of discharge coefficient ratio between experimental and correlation values, for different Reynolds number. In general, suitable agreement is apparent, with overall $4 \%$ and $1 \%$ error percentages for data comparison with correlation Equations (9) and (10), respectively. Overall, pressure losses reduction for the system occurs as $\mathrm{G}$ is greater than 0.0067 when $\operatorname{Re}_{j}$ is lower than 5000 and occurs as $G$ is greater than 0.0333 when Re is higher than 5000 .

$$
\begin{aligned}
\mathrm{C}_{\mathrm{d}} / \mathrm{C}_{\mathrm{d} 0} & =\left\{\begin{array}{r}
7.5 \times \mathrm{G}+0.95, \operatorname{Re}<5000(\mathrm{a}) \\
3.0 \times \mathrm{G}+0.90, \operatorname{Re}>5000(\mathrm{~b})
\end{array}\right. \\
\mathrm{G} & =\ln \left(\frac{\mathrm{h}}{\mathrm{D}}\right) \times\left(0.0287 \times \mathrm{Re}^{-0.2}\right)
\end{aligned}
$$

where $\mathrm{h}$ is micro cooling units height, $\mathrm{D}$ is impingement hole diameter.

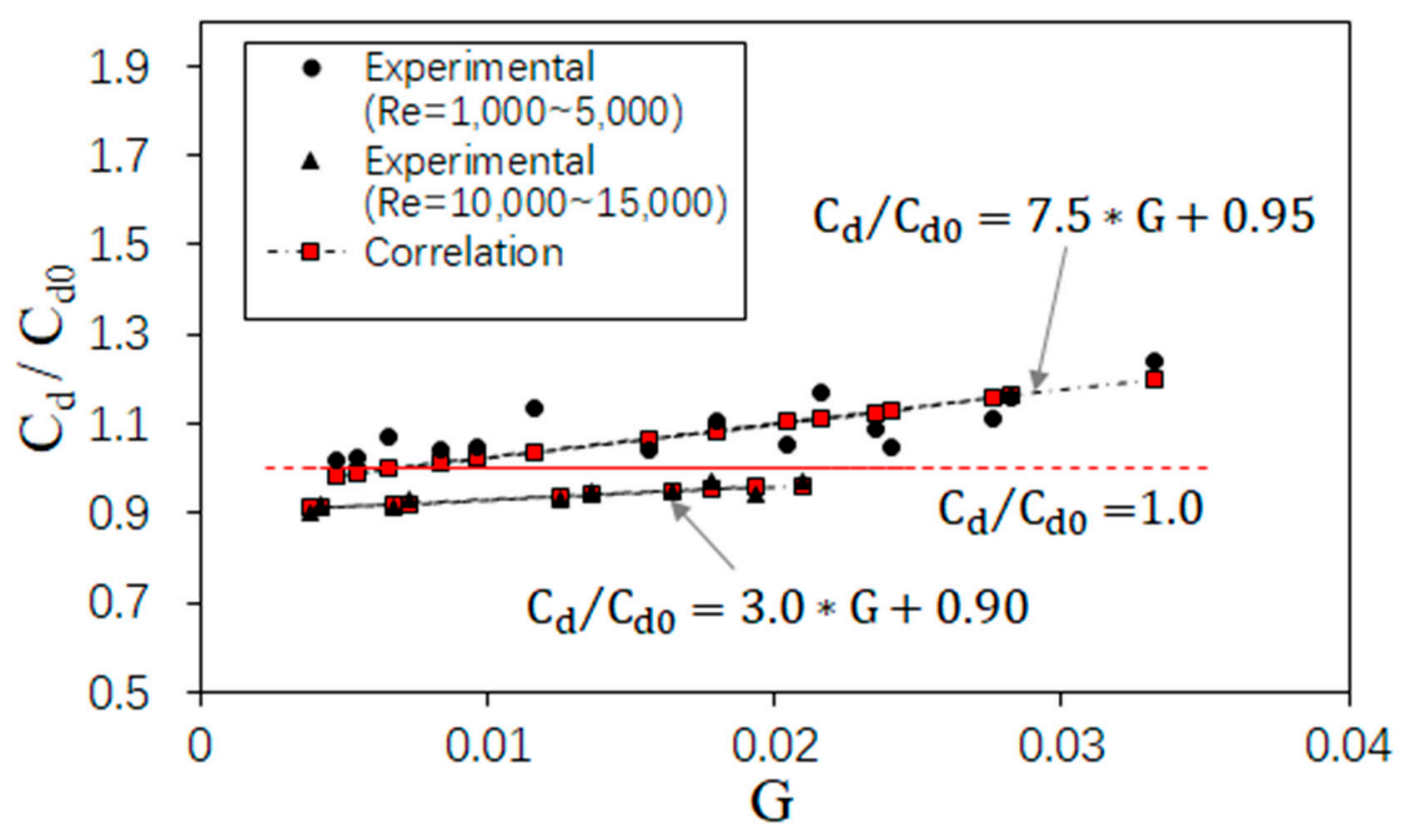

Figure 23. Discharge coefficient ratio as dependent upon $G$ for $\operatorname{Re}_{j}=1000,2500,5000,10,000$, and 15,000, including comparison with correlation data.

\section{Conclusions}

The present study of impingement target surface micro cooling units shows remarkable potential for improvement of technological advancement by optimizing the heat transfer characteristic for the system. Within the study, the investigation includes effects of varying $\mathrm{Re}_{j}$ and varying micro cooling units height $h$, which demonstrate heat transfer enhancement and pressure losses reduction capability for the fluid system.

(a) When $\operatorname{Re}_{j}=1000$, and 2500, discharge coefficient ratio values show about $2 \sim 18 \%$ and $3 \sim 6 \%$ reductions in pressure losses for system. This is because the flow is within laminar, laminar-turbulent transition.

(b) When compared at particular values of $\mathrm{Re}_{\mathrm{j}}$, it is observed inverse proportional relation between discharge coefficient ratio values and micro cooling units height, which indicates that target plate with a higher micro cooling units height cause greater pressure losses for the system. This is because that the increasing height of the micro cooling units results in the increase in associated generated drag. 
(c) The spatially averaged Nusselt number ratio shows an approximate $20-300 \%$ heat transfer augmentation and increases as micro cooling units height increases. Such results are due to increased thermal transport and near-wall mixing, as the cooling unit elements are higher. It is believed that the micro cooling units along the wall break the viscous sublayer, which is normally formed within the boundary layer on the smooth target surface.

(d) The addition of the micro cooling units is capable of enhancing heater transfer and reduce pressure losses, and in general, does not cause a discernable increment in pressure loss penalty for the system for all the test configurations examined. This is because of the pitch-to-height ratio designed and arranged for micro cooling units elements distributed on the target plate surface.

Author Contributions: Conceptualization, Z.R. and X.L. (Xueying Li); methodology, Z.R. and X.L. (Xueying Li); formal analysis, Z.R.; investigation, Z.R. and X.Y.; data curation, Z.R. and X.L. (Xunfeng $\mathrm{Lu}$ ); writing-original draft preparation, Z.R. and X.Y. (Xueying Li); writing-review and editing, Z.R., X.L. (Xueying Li) and J.R.; supervision, X.L. (Xueying Li) and J.R.; project administration, X.L. (Xueying Li) and J.R. All authors have read and agreed to the published version of the manuscript.

Funding: Please add: This research was funded by the National Natural Science Foundation of China, grant number 51706116.

Institutional Review Board Statement: Not applicable.

Informed Consent Statement: Not applicable.

Data Availability Statement: Not applicable.

Acknowledgments: The authors acknowledge financial support from the National Natural Science Foundation of China (Project Numbers 51706116) and the Tsinghua University Initiative Scientific Research Program. The authors are also grateful to colleagues of Tsinghua University.

Conflicts of Interest: The authors declare no conflict of interest.

\section{Nomenclature}

A

$\mathrm{A}_{1}$

AR

$\mathrm{Bi}$

$\mathrm{C}_{\mathrm{d}}$

C

$\mathrm{D}$

$\mathrm{h}$

h

k

1

L

m

$\mathrm{n}$

$\Delta \mathrm{P}$

$\mathrm{P}_{\mathrm{S}}$

$\mathrm{P}_{\mathrm{t}}$

$\mathrm{q}$

qloss

R

area, $\mathrm{m}^{2}$

lower surface area, $\mathrm{m}^{2}$

wetted area ratio: ratio of wetted surface area to flat projected area

Biot number

discharge coefficient

specific heat

impingement jet hole diameter, $\mathrm{mm}$

micro cooling units height, $\mathrm{mm}$

heat transfer coefficient, $\mathrm{W} /\left(\mathrm{m}^{2} \mathrm{~K}\right)$

thermal conductivity, $\mathrm{W} /(\mathrm{mK})$

characteristic length of Biot number

length of micro cooling units, $\mathrm{mm}$

mass flow rate, $\mathrm{kg} / \mathrm{s}$

number of holes in the impingement plate

differential pressure, $\mathrm{Pa}$

static pressure, $\mathrm{Pa}$

stagnation pressure, $\mathrm{Pa}$

surface heat flux, $\mathrm{W} / \mathrm{m}^{2}$

heat flux due to conduction, $\mathrm{W} / \mathrm{m}^{2}$

heater resistance, $\Omega$ 


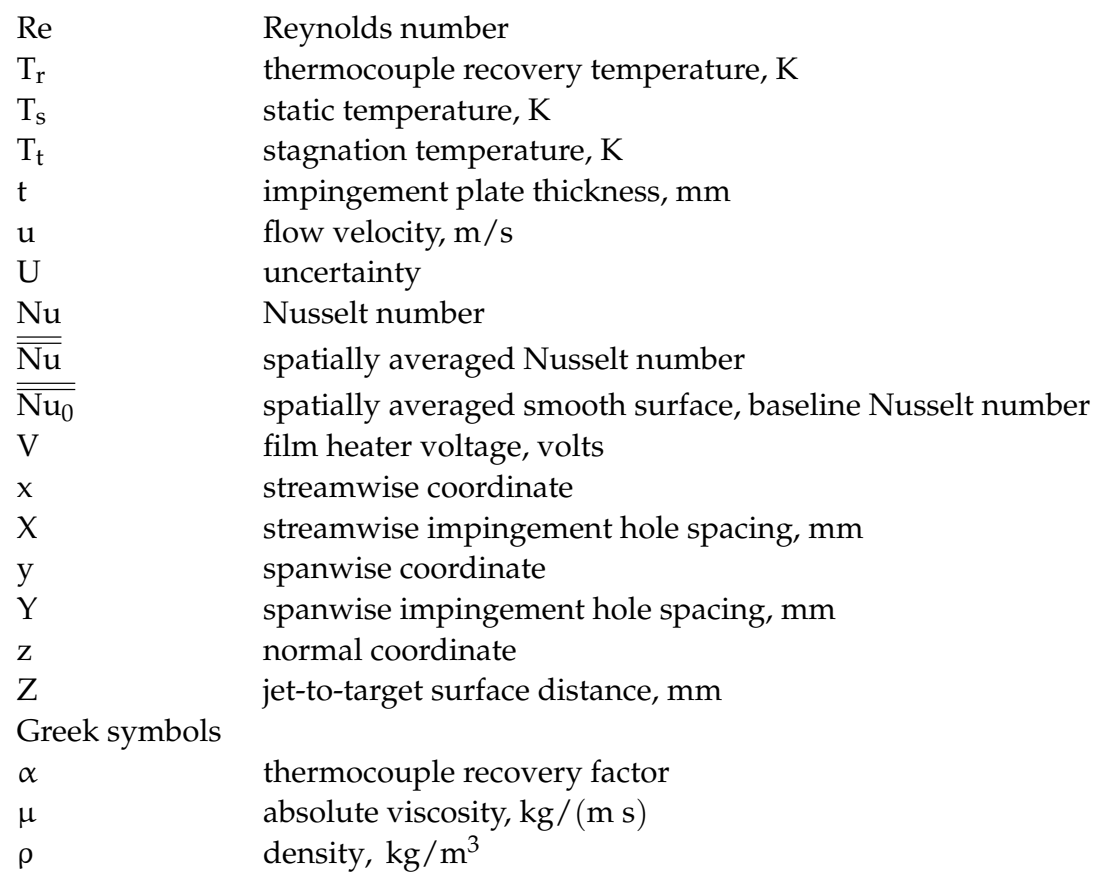

\section{References}

1. Lee, J.; Ren, Z.; Ligrani, P.M.; Fox, M.D.; Moon, H.-K. Crossflows From Jet Array Impingement Cooling: Hole Spacing, Target Plate Distance, Reynolds Number Effects. Int. J. Therm. Sci. 2015, 88, 7-18. [CrossRef]

2. Bunker, R.S. Gas turbine heat transfer: 10 remaining hot gas path challenges; Paper number GT2006-90002. In Proceedings of the ASME TURBO EXPO Gas Turbine and Aeroengine Technical Congress, Exposition, and Users Symposium, Barcelona, Spain, 6-11 May 2006.

3. Kercher, D.M.; Tabakoff, W. Heat Transfer By a Square Array of Round Air Jets Impinging Perpendicular to a Flat Surface Including the Effect of Spent Air. Asme Trans. J. Eng. Power 1970, 92, 73-82. [CrossRef]

4. Chance, J.L. Experimental Investigation of Air Impingement Heat Transfer Under an Array of Round Jets. TAPPI 1974, 57, $108-112$.

5. San, J.Y.; Tsou, Y.M.; Chen, Z.C. Impingement Heat Transfer of Staggered Arrays of Air Jets Confined in a Channel. Int. J. Heat Mass Transf. 2007, 50, 3718-3727. [CrossRef]

6. Lee, J.; Ren, Z.; Ligrani, P.M.; Lee, D.H.; Fox, M.; Moon, H.-K. Cross-Flow Effects on Impingement Array Heat Transfer With Varying Jet-To-Target Plate Distance and Hole Spacing. Int. J. Heat Mass Transf. 2014, 75, 534-544. [CrossRef]

7. Florschuetz, L.W.; Truman, C.R.; Metzger, D.E. Streamwise Flow and Heat Transfer Distributions for Jet Array Impingement With Crossflow. Asme Trans. J. Heat Transf. 1981, 103, 337-342. [CrossRef]

8. Metzger, D.E.; Florschuetz, L.W.; Takeuchi, D.I.; Behee, R.D.; Berry, R.A. Heat Transfer Characteristics for Inline and Staggered Arrays of Circular Jets With Crossflow of Spent Air. Asme Trans. J. Heat Transf. 1979, 101, 526-531. [CrossRef]

9. Bailey, J.C.; Bunker, R.S. Local Heat Transfer and Flow Distributions For Impinging Jet Arrays of Dense and Sparse Extent; Paper No. ASME GT-2002-30473; Turbo Expo 2002: Power for Land, Sea, and Air; ASME: Amsterdam, Netherlands, 6 June 2002.

10. Lee, J.; Ren, Z.; Haegele, J.; Potts, G.; Jin, J.S.; Ligrani, P.M.; Fox, M.; Moon, H.-K. Effects of Jet-To-Target Plate Distance and Reynolds Number on Jet Array Impingement Heat Transfer. ASME Trans. J. Turbomach. 2014, 136, 051013. [CrossRef]

11. Buzzard, W.C.; Ren, Z.; Ligrani, P.M.; Nakamata, C.; Ueguchi, S. Influences of Target Surface Small-Scale Rectangle Roughness on Impingement Jet Array Heat Transfer. Int. J. Heat Mass Transf. 2017, 110, 805-816. [CrossRef]

12. Ligrani, P.M.; Ren, Z.; Buzzard, W.C. Impingement Jet Array Heat Transfer With Small-Scale Cylinder Target Surface Roughness Arrays. Int. J. Heat Mass Transf. 2017, 107, 895-905. [CrossRef]

13. Ren, Z.; Buzzard, W.C.; Ligrani, P.M.; Nakamata, C.; Ueguchi, S. Impingement Jet Array Heat Transfer: Target Surface Roughness Shape, Reynolds Number Effects. AIAA J. Thermophys. Heat Transf. 2017, 31, 346-357. [CrossRef]

14. Nakamata, C.; Okita, Y.; Yamane, T.; Fukuyama, Y.; Yoshida, T. Effect of Roughened Elements on Target Surface and Cooling Hole Shape on Impingement Cooling Effectiveness. Paper IGTC2011-0003. In Proceedings of the 10th International Gas Turbine Congress, Osaka, Japan, 15-20 November 2011.

15. Singh, P.; Ekkad, S.V. Effects of Spent Air Removal Scheme on Internal-Side Heat Transfer in an Impingement-Effusion System at Low Jet-To-Target Plate Spacing. Int. J. Heat Mass Transf. 2017, 108, 998-1010. [CrossRef]

16. Spring, S.; Xing, Y.; Weigand, B. An experimental and numerical study of heat transfer from arrays of impinging jets with surface ribs, ASME Trans. J. Heat Transf. 2012, 134, 082201-01-082201-09. [CrossRef]

17. Brakmann, R.; Chen, L.; Weigand, B.; Crawford, M. Experimental and numerical heat transfer investigation of an impinging jet array on a target plate roughened by cubic micro pin fins. J. Turbomach. 2016, 138, 11. [CrossRef] 
18. Sutherland's Formula. McGraw-Hill Dictionary of Scientific E Technical Terms, 6E. 2003; The McGraw-Hill Companies, Inc.: New York, NY, USA, 2021.

19. Lu, X.; Li, W.; Li, X.; Ren, J.; Jiang, H.; Ligrani, P. Flow and Heat Transfer Characteristics of Micro Pin-Fins under Jet Impingement Arrays. Int. J. Heat Mass Transf. 2019, 143, 118416. [CrossRef]

20. Moffat, R.J. Contributions to the Theory of Single-Sample Uncertainty Analysis. Asme Trans. J. Fluids Eng. 1982, 104, 250-260. [CrossRef]

21. Florschuetz, L.W.; Berry, C.R.; Metzger, D.E. Streamwise Flow and Heat Transfer Coefficients for Inline and Staggered Arrays of Circular Jets with Crossflow of Spent Air. Asme Trans. J. Heat Transf. 1981, 102, 132-137. [CrossRef]

22. Ligrani, P.M.; Mclnturff, P.; Suzuki, M.; Nakamata, C. Winglet-pair target surface roughness influences on impingement jet array heat transfer. J. Enhanc. Heat Transf. 2018, 25, 1-21. [CrossRef] 